\title{
The Effect of Drought on
} Transcriptome and Hormonal Profiles in Barley Genotypes With Contrasting Drought Tolerance

\author{
Amal Harb ${ }^{1,2 *}$, Craig Simpson ${ }^{3}$, Wenbin Guo ${ }^{4}$, Ganesan Govindan ${ }^{1}$, Vijaya Gopal Kakani ${ }^{5}$ \\ and Ramanjulu Sunkar ${ }^{1 *}$ \\ 1 Department of Biochemistry and Molecular Biology, Oklahoma State University, Stillwater, OK, United States, ${ }^{2}$ Department \\ of Biological Sciences, Faculty of Science, Yarmouk University, Irbid, Jordan, ${ }^{3}$ Cell and Molecular Sciences, The James \\ Hutton Institute, Dundee, United Kingdom, ${ }^{4}$ Informatics and Computational Sciences, The James Hutton Institute, Dundee, \\ United Kingdom, ${ }^{5}$ Department of Plant and Soil Science, Oklahoma State University, Stillwater, OK, United States
}

\section{OPEN ACCESS}

Edited by:

Raul Antonio Sperotto,

Universidade do Vale do Taquari-

Univates, Brazi

Reviewed by:

Viswanathan Chinnusamy

Indian Agricultural Research Institute

(ICAR), India

Nikolai Borisjuk,

Huaiyin Normal University, China

*Correspondence:

Amal Harb

aharb@yu.edu.jo;

harbhope78@gmail.com

Ramanjulu Sunkar

ramanjulu.sunkar@okstate.edu

Specialty section:

This article was submitted to

Plant Abiotic Stress,

a section of the journa

Frontiers in Plant Science

Received: 17 October 2020 Accepted: 27 November 2020

Published: 23 December 2020

Citation:

Harb A, Simpson C, Guo W, Govindan G, Kakani VG and Sunkar R

(2020) The Effect of Drought on Transcriptome and Hormonal Profiles in Barley Genotypes With Contrasting Drought Tolerance.

Front. Plant Sci. 11:618491 doi: 10.3389/fp/s.2020.618491
Like many cereal crops, barley is also negatively affected by drought stress. However, due to its simple genome as well as enhanced stress resilient nature compared to rice and wheat, barley has been considered as a model to decipher drought tolerance in cereals. In the present study, transcriptomic and hormonal profiles along with several biochemical features were compared between drought-tolerant (Otis) and drought-sensitive (Baronesse) barley genotypes subjected to drought to identify molecular and biochemical differences between the genotypes. The drought-induced decrease in the leaf relative water content, net photosynthesis, and biomass accumulation was relatively low in Otis compared to Baronesse. The hormonal profiles did not reveal significant differences for majority of the compounds other than the GA20 and the cis-zeatin-o-glucoside (c-ZOG), whose levels were greatly increased in Otis compared to Baronesse under drought. The major differences that emerged from the transcriptome analysis are; (1), the overall number of differentially expressed genes was relatively low in drought-tolerant Otis compared to drought-sensitive Baronesse; (2), a wax biosynthesis gene (CER1), and NAC transcription factors were specifically induced in Otis but not in Baronesse; (3), the degree of upregulation of betaine aldehyde dehydrogenase and a homeobox transcription factor (genes with proven roles in imparting drought tolerance), was greater in Otis compared to Baronesse; (4) the extent of downregulation of gene expression profiles for proteins of the reaction center photosystem II (PSII) (D1 and D2) was low in Otis compared to Baronesse; and, (5), alternative splicing (AS) was also found to differ between the genotypes under drought. Taken together, the overall transcriptional responses were low in drought-tolerant Otis but the genes that could confer drought tolerance were either specifically induced or greatly upregulated in the tolerant genotype and these differences could be important for drought tolerance in barley.

Keywords: drought tolerance, barley, photosynthesis, proline, RNA-Seq, differential gene expression, alternative splicing 


\section{INTRODUCTION}

Drought negatively impacts the growth and productivity of many important crops (Bartels and Sunkar, 2005; Kim et al., 2019). Future predictions indicate that drought will worsen, challenging worldwide food security and the needs of an increasing human population (Meza et al., 2020). Indeed, hunger, famine, and malnutrition are expected due to climate change and drought, in addition to other social and political factors (Lobell et al., 2011; Lesk et al., 2016; Cafiero et al., 2018).

Drought is known to disrupt the hormonal balance in plants, which plays an important role in stress tolerance (Peleg and Blumwald, 2011; Bielach et al., 2017; Ullah et al., 2018). The enhanced accumulation of Abscisic acid (ABA) is a hallmark of plant response to drought, which in turn controls the stomatal closure to decrease the transpiration under drought (Munemasa et al., 2015; Ullah et al., 2018). Auxins regulate root growth in response to abiotic stresses including drought (Korver et al., 2018). Similarly, the Gibberellin (GA) mediates many responses to drought. GA concentration is reduced, and the DELLA regulators accumulate, which could be attributed to the retarded growth under drought (Colebrook et al., 2014). Cytokinins (CKs) and their metabolism are important in plants' adaptation to different abiotic stresses including drought ( $\mathrm{Ha}$ et al., 2012; Pavlu et al., 2018). Both positive and negative effects of CKs on drought tolerance were reported (Zwack and Rashotte, 2015). These observations suggest that the fine-tuned hormonal homeostasis during stress conditions plays an important role in plant's response to abiotic stresses.

Barley (Hordeum vulgare L.) is the fourth most important crop plant in terms of production and harvested area (Giraldo et al., 2019). It is a relatively drought resistant crop and is cultivated globally in more than 100 countries (Hiei et al., 2014; Giraldo et al., 2019). Barley is considered as an important model system for dissecting drought tolerance in cereals because of its ability to tolerate drought better than the cereals such as rice and wheat. Moreover, it has a reliable genetic and molecular infrastructure (Dawson et al., 2015).

Barley subjected to drought stress has been investigated previously (Ozturk et al., 2002; Diab et al., 2004; Talamé et al., 2007; Guo et al., 2009; de Mezer et al., 2014; Sallam et al., 2019). Drought significantly reduced the net photosynthetic rate, stomatal conductance, and transpiration in barley (Harb and Samarah, 2015; Mejri et al., 2016; Schmid et al., 2016; Hasanuzzaman et al., 2019). Tibetan barley genotypes subjected to drought revealed the importance of ABA-dependent and ABA-independent signaling pathways during drought, while genes linked to photosynthesis appears to be important during recovery from drought (Zeng et al., 2016). Comparison of barley spikelets' responses in drought-sensitive and droughttolerant lines revealed a role for a set of more recently evolved genes in the tolerant lines (Hübner et al., 2015). A droughtresistant line exposed to drought stress over 30 days showed acclimation to the stress while the gene expression profiles in this genotype did not differ compared to a drought-sensitive cultivar (Cantalapiedra et al., 2017). Studies also indicated that maintaining a low background expression of drought tolerance related genes under mild stress allows barley to respond more quickly with the onset of the drought stress (Janiak et al., 2019). Furthermore, recent studies underscored the importance of AS in drought-responsive gene expression in barley (Cantalapiedra et al., 2017). By and large, these reports reveal a complex interaction between multiple mechanisms and processes that differ between genotypes/landraces, tissue analyzed and duration of the stress (Hübner et al., 2015; Zeng et al., 2016; Cantalapiedra et al., 2017; Wang et al., 2018). They also highlight the importance of analyzing additional contrasting genotypes to better understand the drought tolerance processes in barley. Deep large-scale transcriptome sequencing allows expression at an individual gene transcript level to be monitored. New quasi-mapping programs (kallisto, salmon) facilitate rapid and highly accurate measurement of transcript level expression but require a comprehensive and accurate reference transcriptome. A first version reference transcript dataset for barley (BaRTv1.0) has recently been established that facilitates measurement of dynamic reprogramming of gene expression in barley and captures post-transcriptional regulation (Rapazote-Flores et al., 2019). In this study, drought-tolerant (Otis) has been compared with drought-sensitive (Baronesse) to identify biochemical and molecular differences associated with differential sensitivities. The drought-responsive RNA-Seq analysis revealed a greater number of differentially expressed genes in Baronesse than in Otis. Interestingly, several genes with proven roles in drought tolerance such as NAC genes, wax biosynthesis gene (CER1), a beta-expansin, and Armadillo (ARM) repeat superfamily were only induced in Otis but not in Baronesse. By contrast, the degree of inhibition of genes associated with PSII (D1 and D2) was much stronger in Baronesse. Furthermore, AS was also found to differ between the genotypes under drought.

\section{MATERIALS AND METHODS}

\section{Plant Material}

Seeds of Otis and Baronesse genotypes were obtained from Dr. Harold Bockelman, National Small Grains Collection (NSGC), U.S. Department of Agriculture - Agricultural Research Service, Aberdeen, Idaho, USA. Otis is a two-rowed, spring feed barley with high growth and yield in drylands (Mornhinweg et al., 2009). This genotype was developed for growth in dry environments and released by Colorado State University in 1951. Baronesse is a two-rowed, spring, feed barley cultivar that was donated by Peterson Seed Company Incorporation to the NSGC in 1993.

\section{Growth and Relative Water Content Measurements}

Barley seeds were germinated on moist papers and kept in darkness at $24^{\circ} \mathrm{C}$. After 3 days, seedlings were transferred to $19 \times$ $13.5 \times 17 \mathrm{~cm}$ plastic pots filled with BM1 potting medium (peat moss (75-85\%), vermiculite, perlite and wetting agent) (Berger, Canada). To ensure both genotypes experienced the same level of drought stress during the treatment, two seedlings of each genotype were transferred to the same pot. The plants were grown in a growth chamber maintained at $25 / 17^{\circ} \mathrm{C}$ (day/night temperature), $14 / 10 \mathrm{~h}$ (day/night cycle), $400 \mu$ mole $^{-1} \mathrm{~s}^{-1}$ light intensity and 50\% humidity. Barely plants were fertilized twice 
(first fertilization was 2 days after seedling transfer to pots, and the second was 10 days after the first fertilization) with MiracleGroß Water-Soluble All-Purpose Plant Food (Scotts Miracle Gro, USA). Drought treatment was initiated at the tillering stage Z21 (Zadoks scale) (Zadoks et al., 1974) at which the pots were divided into two groups: the control (well-watered) group and the drought-treated group. For the control group, plants were watered every other day. For imposing drought, watering was withheld, and plants were allowed to experience progressive drought $(\mathrm{pDr})$. For the determination of growth, only main shoot (the shoot that appeared before the tillering stage) was chosen because the differences in the number of tillers among the individual plants of the same genotype varied. After 7 days of $\mathrm{pDr}$, the leaf relative water content (LRWC) was calculated as described (Schonfeld et al., 1988) LRWC\% = (Fresh weight-Dry weight)/ (Turgid weight-Dry weight) X 100.

\section{Gas Exchange Measurements}

For assessing photosynthesis-associated parameters, after 5 days of $\mathrm{pDr}$ (initial wilting), net photosynthetic rate, stomatal conductance, internal $\mathrm{CO}_{2}$ concentration, and transpiration rate of the control and the drought-treated plants were measured on the youngest fully expanded leaf of the control and droughttreated plants (8 plants of each genotype per treatment) using LICOR 6400XT (LI-COR Inc., NE, USA). The following conditions were set for LICOR measurements: flow rate of 300 $\mathrm{mmol} \mathrm{s}{ }^{-1}, \mathrm{CO}_{2}$ at $400 \mathrm{mmol}$, leaf temperature $25^{\circ} \mathrm{C}$, and relative humidity of $50 \%$.

\section{Proline Content}

Proline was analyzed according to Carillo and Gibon (2011). Fresh samples from the youngest fully expanded leaf were homogenized using one $\mathrm{ml}$ extraction solution (70 ethanol: 30 water). Then, a volume of $100 \mu \mathrm{l}$ of the extract was added to 200 $\mu l$ of the reaction mixture (1\% (w/v) ninhydrin, $60 \%(\mathrm{v} / \mathrm{v})$ acetic acid, and $20 \%(\mathrm{v} / \mathrm{v})$ ethanol). The reaction was kept in a boiling water bath for $20 \mathrm{~min}$, and then kept on ice for stopping the reaction. The absorbance of the reaction mixture was measured at $520 \mathrm{~nm}$.

\section{Malondialdehyde Accumulation}

Oxidative stress was determined by quantification of the malondialdehyde (MDA) levels (Heath and Packer, 1968) with some modifications. Samples of known fresh weight of the youngest fully expanded leaf were collected and snap frozen in liquid nitrogen. The samples were homogenized in $1 \mathrm{ml}$ of $0.1 \%$ (w/v) trichloroacetic acid (TCA). Then, they were centrifuged at $4,100 \mathrm{rpm}$ for $10 \mathrm{~min}$. About $100 \mu \mathrm{l}$ of the supernatant was added to $400 \mu \mathrm{l}$ of $0.5 \%(\mathrm{w} / \mathrm{v})$ thiobarbituric acid in $20 \%(\mathrm{w} / \mathrm{v}) \mathrm{TCA}$ and the homogenates were boiled at $95^{\circ} \mathrm{C}$ for $30 \mathrm{~min}$ and the reaction was stopped by cooling the tubes on ice. The reaction mixture was centrifuged, and the absorbance was read at $532 \mathrm{~nm}$ and $600 \mathrm{~nm}$. After subtracting the non-specific absorbance at $600 \mathrm{~nm}$, the MDA concentration was determined by its extinction coefficient of $155 \mathrm{mM}^{-1} \mathrm{~cm}^{-1}$.

\section{Hormonal Profiling}

After 5 days of pDr (the initial wilting stage), three biological replicates (ten leaves from 10 different plants were used for each biological replicate) of the youngest fully expanded leaves of the control and the drought-treated plants were collected, snap frozen in liquid nitrogen and kept at $-80^{\circ} \mathrm{C}$. The frozen samples were lyophilized and used for hormonal analysis. The levels of major hormones and their metabolites were quantified using UPLC ESI-MS/MS by the National Research Council of Canada (Saskatchewan, Canada). The analyzed hormones and metabolites are: cis-abscisic acid (ABA), abscisic acid glucose ester (ABAGE), dihydrophaseic acid (DPA), phaseic acid (PA), 7'-hydroxy-abscisic acid (7'OH-ABA), neo-phaseic acid (neoPA), trans-abscisic acid (t-ABA), gibberellin 1 (GA1), GA3, GA4, GA7, GA8, GA9, GA19, GA20, GA24, GA29, GA34, GA44, GA51, GA53, indole-3-acetic acid (IAA), N-(indole-3-yl-acetyl)aspartic acid (IAA-Asp), N-(indole-3-yl-acetyl)-glutamic acid (IAA-Glu), N-(indole-3-yl-acetyl)-alanine (IAA-Ala), N-(indole3-yl-acetyl)-leucine (IAA-Leu), indole-3-butyric acid (IBA), (trans) zeatin-O-glucoside (t-ZOG), (cis) zeatin-O-glucoside (cZOG), (trans) zeatin (t-Z), (cis) zeatin (c-Z), dihydrozeatin (dhZ), (trans) zeatin riboside (t-ZR), (cis) zeatin riboside (c$\mathrm{ZR}$ ), dihydrozeatin riboside (dhZR), isopentenyladenine (iP), isopentenyladenosine (iPR), and kinetin (KIN).

\section{Statistical Analysis}

The morphological, physiological, and biochemical data were analyzed using Student's $t$-test, 2-tailed distribution, and type 3 (2-sample unequal variance) (Excel, Microsoft, USA). A difference in means at value $<0.05$ was considered significant.

\section{RNA Sequencing}

Three biological samples per genotype per treatment were collected from the youngest fully expanded leaf of 10 plants/sample from the control and the drought treated plants after 5 days of drought (initial wilting stage). The total RNA was extracted following the standard TRIzol method. The RNA integrity was checked with Agilent Technologies 2100 Bioanalyzer (Agilent Technologies, California, USA). Poly(A) tail-containing mRNAs were purified using oligo-(dT) magnetic beads with two rounds of purification. The purified poly(A) RNA was fragmented, and the library was constructed by synthesizing first strand cDNA, followed by second strand cDNA with dUTP, end repair, 3 adenylation, adaptor ligation, Uracil-DNAGlycosylase (UDG) treatment, and PCR. Quality analysis and quantification of the sequencing library were performed using Agilent Technologies 2100 Bioanalyzer High Sensitivity DNA Chip. Paired-ended sequencing was performed on Illumina's NovaSeq 6000 sequencing system (LC Sciences, TX, USA). To remove the reads that contained adaptor contamination, low quality bases and undetermined bases in the sequenced RNA-seq libraries, Cutadapt (Martin, 2011) and perl scripts developed in house were used. Then, sequence quality was verified using FastQC (http://www.bioinformatics.babraham.ac.uk/projects/ fastqc/). 


\section{Differential Expression and Differential Alternative Splicing Analyses}

The RNA-seq data had 4 treatment groups: Otis, drought treatment (OD) Otis, watered treatment (OW); Baronesse drought treatment (BD) and Baronesse, watered treatment (BW) and each had 3 biological replicates (12 samples in total). Transcript quantifications were generated using Salmon (Patro et al., 2017) and the Barley transcriptome BARTv1.0-QUASI (https://ics.hutton.ac.uk/barleyrtd/index.html) (Rapazote-Flores et al., 2019). The 3D RNA-seq analysis App was used for differential expression (DE) and differential alternative splicing (DAS) analysis (Calixto et al., 2018; Guo et al., 2019). In the pipeline, expressed transcripts were identified when found in $\geq 2$ of the 12 samples with count per million reads (CPM) $\geq$ 1 , which provided an optimal mean-variance trend of the read count distribution. The Trimmed Mean of M-values (TMM) method was used to normalize the gene and transcript read counts to $\log _{2}$-CPM (Bullard et al., 2010). Limma-VoomWeights method was used for DE and DAS (Law et al., 2014; Ritchie et al., 2015). To compare the expression changes between conditions of experimental design, the contrast groups were set as ODOW, BD-BW, OW-BW, OD-BD. For DE genes, the $\log _{2}$ fold change $\left(L_{2} F C\right)$ of gene abundance were calculated based on contrast groups and $p$-values of multiple testing were adjusted with Benjamini-Hochberg $(\mathrm{BH})$ to correct for false discovery rate (FDR) (Benjamini and Yekutieli, 2001). A gene was significantly $\mathrm{DE}$ in a contrast group if it had adjusted $p<0.01$ and $L_{2} F C \geq 1$. For DAS genes, each individual transcript $L_{2} F C$ were compared to gene level $L_{2} F C$, which was calculated as the weighted average of $L_{2} F C s$ of all transcripts of the gene. Then $p$-values of individual transcript comparison were summarized to a single gene level $p$-value with an F-test. A gene was significantly DAS in a contrast group if it had an adjusted $p<0.01$ and any of its transcripts had a $\Delta$ Percent Spliced $(\Delta \mathrm{PS})$ ratio $\geq 0.1$ (see Supplementary Report).

\section{Functional Analysis of the DE Genes}

The Venn diagram generator of the Bioinformatics and Evolutionary Genomics lab at Ghent University and VIB, Belgium was used to find the unique and the common DE genes in the four contrast groups (http://bioinformatics.psb.ugent.be/ webtools/Venn/).

Gene Ontology Tags were applied to the BaRT transcripts using Protein Annotation with Z-score (PANNZER) (Törönen et al., 2018) to produce GO annotations for 25,906 BaRT genes. GO functional enrichment analysis of the DE genes was done using g:profiler (https://biit.cs.ut.ee/gprofiler/gost) (Raudvere et al., 2019) with reference GO annotation dataset file BART_V_1.gmt (https://ics.hutton.ac.uk/barleyrtd/GO_ enrichment.html).

The analysis of transcription factors (TFs) and kinases were performed using iTAK online (Zheng et al., 2016). First, the HORV annotation was retrieved for each of DE BaRT genes. Then, BioMart from Ensembl plants was used to get the protein sequence for each gene using Ensembl plants 47 as the database and Horduem vulgare genes (IBSC V2) as the dataset (https://plants.ensembl.org/biomart/martview/ 31c188c3a5aff85045c3cceb489e5597). Protein sequences of the
DE genes were the input for the transcription factor and kinase analysis by iTAK online.

\section{Quantitative Real-Time (qRT) PCR Analysis}

Total RNA was used for cDNA conversion and the qRT PCR reactions were performed using the Light Cycler 96 system (Roche). Each PCR reaction was performed on two independent biological samples with two technical replicates. The relative expression levels of the target genes were calculated using the formula 2- $\Delta \Delta \mathrm{Ct}$ (Livak and Schmittgen, 2001). Fold change was calculated for the drought treated plants relative to the wellwatered control, but for cellulose synthase and phenylalanine ammonia lyase the fold change was also calculated for Otis control relative to Baronesse control. Cyclophilin A (BART1_0p42566) was used as reference gene for data normalization (Burton et al., 2004). Supplementary Table 1 shows the list of primers used.

\section{RESULTS}

\section{Morphological and Physiological Changes in Barley Genotypes Under Drought}

Two barley genotypes with expected differences in resistance to drought were deprived of water to examine morphological and physiological differences between the two genotypes. The morphology of Otis and Baronesse after 7 days of drought is shown in Figure 1A. At this stage of drought, the leaves of both genotypes were severe wilting, and yellowing. The fresh weight of the main shoot of Baronesse was reduced by $49.4 \%$ of the control compared to $30.6 \%$ reduction in Otis (Figure 1B). The dry weight of the main shoot of Baronesse was significantly reduced by $18.7 \%$ compared to $0 \%$ reduction in Otis (Figure 1C).

In response to drought, the LRWC was significantly reduced in Baronesse compared to Otis (43.9 and 50.2\% compared to 95.1 and $88.4 \%$ of the control, respectively). At this level of drought, LRWC was $58 \%$ of the control in Otis, and $46.2 \%$ in Baronesse (Figure 2A). In general, the two genotypes showed a significant decrease in the photosynthetic characteristics $\left[\mathrm{CO}_{2}\right.$ assimilation rate $\left(\mathrm{P}_{\mathrm{N}}\right)$, stomatal conductance (gs), and transpiration rate $\left.(\mathrm{E})\right]$ under drought stress (Figures 2B-D). Under drought, $\mathrm{P}_{\mathrm{N}}$ was $63 \%$ and $56 \%$ of the control in Otis and Baronesse, respectively. A similar trend was observed for gs and E (Figures 2C,D). In the drought-treated Otis, the gs and E showed 24 and $27 \%$ of the control, respectively, whereas these were 19 and $21 \%$ of the control, respectively, in Baronesse. Under well-watered conditions, Otis showed significantly less gs and E (0.092 and $\left.2.31 \mathrm{mmol} \mathrm{m}^{-2} \mathrm{~S}^{-1}\right)$ than Baronesse $\left(0.148\right.$ and $3.72 \mathrm{mmol} \mathrm{m}^{-2}$ $\left.\mathrm{S}^{-1}\right)$. Both morphological and physiological tests show that both genotypes respond to the loss of water, but Otis shows greater endurance under these conditions.

\section{Biochemical and Hormonal Changes in Barley Genotypes Under Drought}

The differential responses between the barley genotypes were further assessed using biochemical and hormonal profiles. Proline accumulation was frequently observed in plants subjected to drought. Drought stress significantly increased proline content 

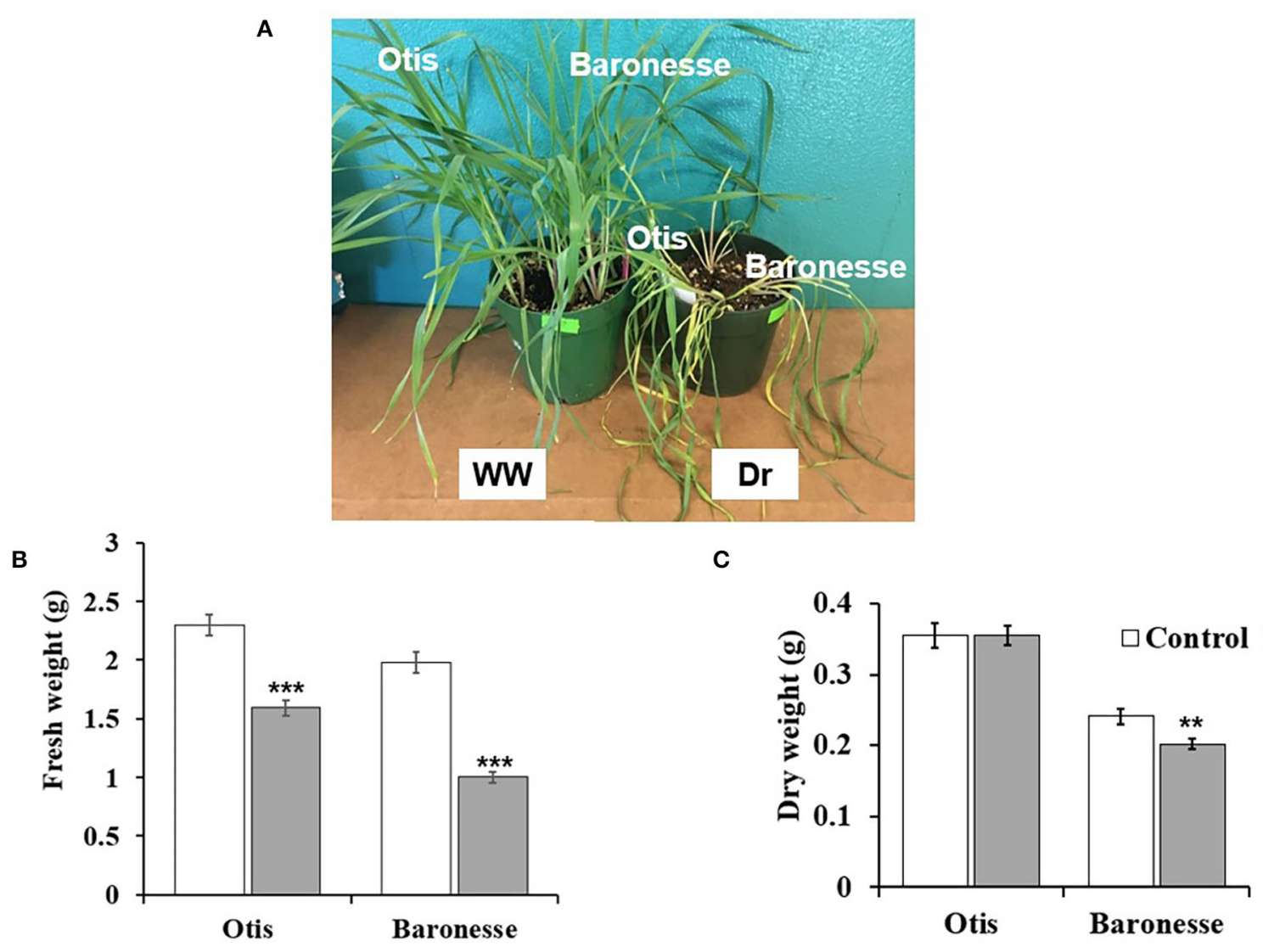

FIGURE 1 | Morphological changes between Otis and Baronesse under drought stress. (A) Barley plants of Otis and Baronesse under well-watered (WW) and drought (Dr) conditions. (B) Fresh weight (FW) of the main shoot (g). (C) Dry weight (DW) of the main shoot (g). Bars represent standard errors of the means. $N=10$ plants. ${ }^{\star \star} P<0.01$ and ${ }^{\star \star \star} P<0.001$.

in the leaves of both genotypes. However, the accumulation found to be higher in Otis (86.94 $\mu \mathrm{mol}$ g-1 FW) compared to Baronesse (43.27 $\mu \mathrm{mol}$ g-1) (Figure 3A). Differential gene expression analysis of proline synthesis and turnover pathway genes further support the accumulation of proline in the leaves under water deficit stress (Supplementary Figure 1). The amount of lipid peroxidation (quantified as MDA) has been often correlated with the degree of stress-induced injury. The concentration of MDA was increased in both the genotypes, although the increase was significant only in the case of Baronesse (Figure 3B).

Changes in the major hormonal groups (ABA, auxins, cytokinins, and GAs) and their metabolites were analyzed in Otis and Baronessse at the initial wilting stage of pDr. The levels of $\mathrm{ABA}$ and its metabolites such as DPA, ABGE, and PA were significantly increased in the drought-treated Otis and Baronesse compared to their respective well-watered controls (Figure 3C). The concentration of $\mathrm{ABA}$ and its metabolites such as $7^{\circ} \mathrm{OH}$ $\mathrm{ABA}$, neo-PA, and t-ABA was not significantly different between the genotypes under both conditions. In the drought-treated Otis, the concentration of $\mathrm{ABA}, 7^{\circ} \mathrm{OH} \mathrm{ABA}$, neo-PA, and $\mathrm{t}$ $\mathrm{ABA}$ was $1,528.71,61.82,50.69$, and $18.22 \mathrm{ng}$ g-1 dry weight
(DW), respectively, while their concentration in the droughttreated Baronesse was 1,882.68, 80.96, 60.82, and $22.54 \mathrm{ng}$ g-1 DW, respectively.

The analysis of 14 GAs including GA19 did not reveal significant differences between the genotypes both under well-watered and drought conditions (Figure 3D). However, GA20 was only detected in the drought-treated Otis but not in Baronesse. This observation indicates that the GA20 is specifically induced under drought in drought-tolerant Otis.

Among the auxins, the IAA was detected in both the genotypes under well-watered as well as drought conditions. However, no significant differences were observed between the genotypes under both the conditions (Figure 3D).

The response of cytokinins, specifically t-ZOG accumulation under drought did not reveal significant differences between the genotypes compared to their respective controls (Figure 3D). However, the c-ZOG was significantly increased in the droughttreated Otis but not in Baronesse (Figure 3D). The concentration of c-ZOG was 496.85, and $177.22 \mathrm{ng}$ g-1 DW in the droughttreated and the control plants of Otis genotype, respectively. Similarly, the iPR levels were increased in both the genotypes under drought but the degree of increase was higher in Otis 
A

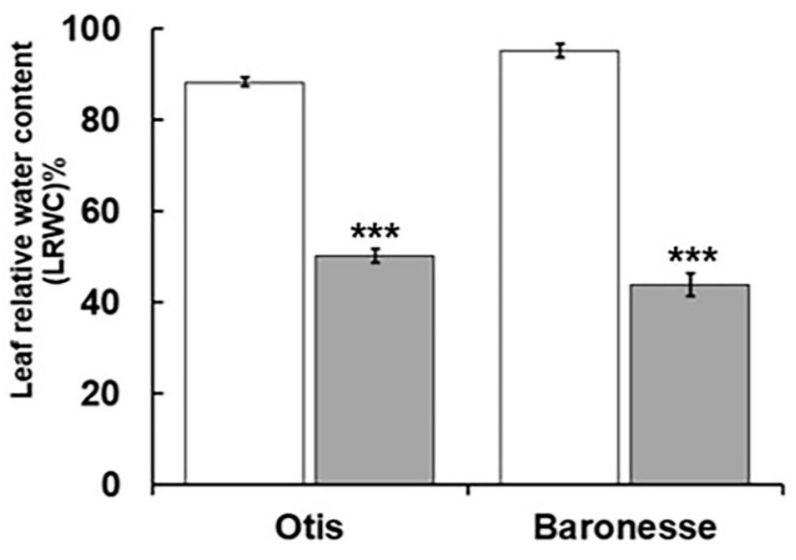

C

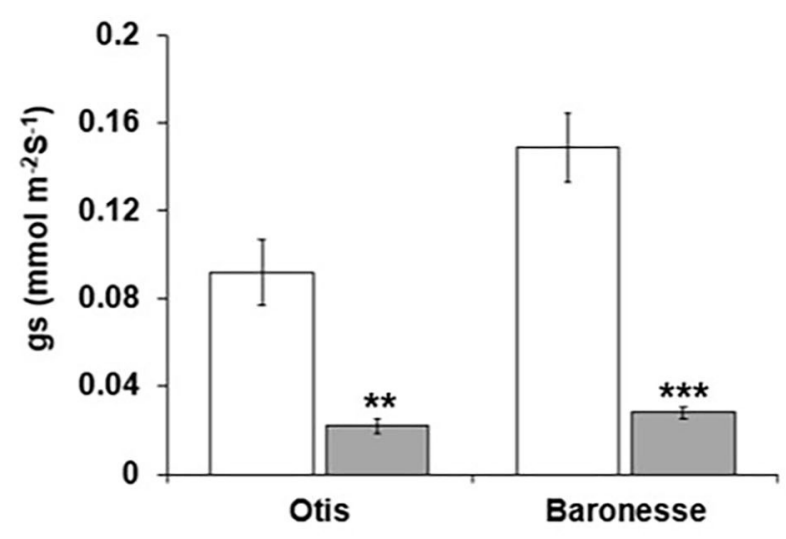

B

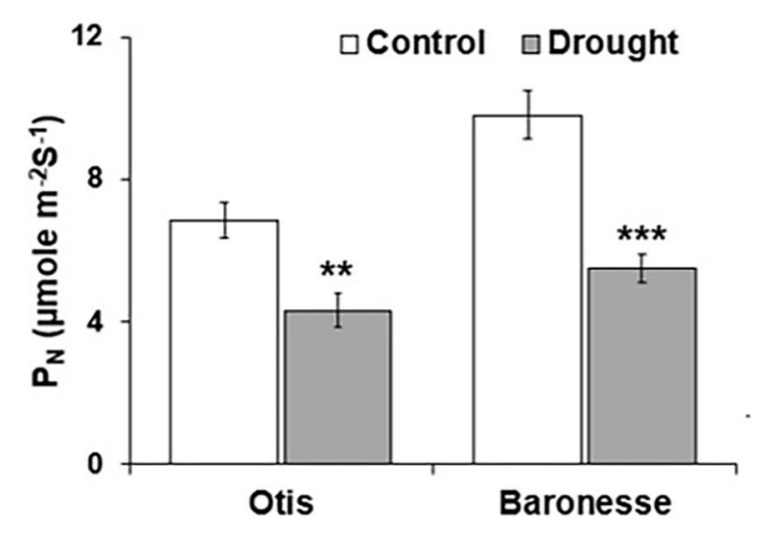

D

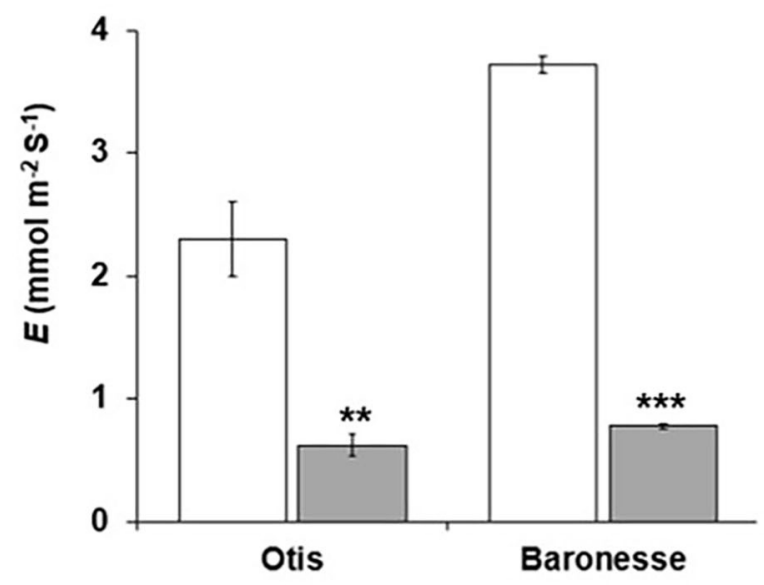

FIGURE 2 | Physiological changes in Otis and Baroness under drought. (A) LRWC. (B) Net photosynthetic rate (PN). (C) Stomatal conductance (gs). (D) Transpiration rate $(E)$. Values are the means of 10 plants for LRWC and 6 plants for photosynthesis measurements. Bars represent standard errors of the means. ${ }^{\star \star} P<0.01$ and ${ }^{\star \star \star} P<0.001$.

than in Baronesse (3.32 and $2.25 \mathrm{ng}$ g-1 DW in the droughttreated and 1.58 and $1.92 \mathrm{ng} \mathrm{g-1} \mathrm{DW} \mathrm{in} \mathrm{the} \mathrm{controls} \mathrm{of} \mathrm{Otis} \mathrm{and}$ Baronesse, respectively).

\section{Overview of the RNA-Seq Analysis of Drought Response in Two Barley Genotypes}

RNA sequencing resulted in at least 40 million paired end reads per sample. The abundance of RNA transcripts in each Otis and Baronesse replicated samples were determined using Salmon and the reference transcript dataset BaRTv1.0. The raw RNA-Seq data has 176,343 transcripts and 59,930 genes After data processing to remove poorly expressed transcripts, there were 57,971 expressed transcripts and 23,970 genes. Principal Component Analysis (PCA) was performed using gene level $\log _{2}$ CPM values of the data to visualize RNA-seq data variation between the samples and replicates. The PCA scatter plot shows that replicates of the watered samples of Otis and Baronesse form distinct groups highlighting differences between the two genotypes. The watered samples were also distinct from the water deprived samples which showed less distinct grouping due to some variation between the replicates but both drought treated genotypes remained distinct (Figure 4). Differential gene expression analysis was calculated for four contrast groups (OD$\mathrm{OW}, \mathrm{BD}-\mathrm{BW}, \mathrm{OW}-\mathrm{BW}$, and OD-BD) to compare the differences in gene expression between genotypes Otis and Baronesse $(\mathrm{O}$ and $B$, respectively), and between drought (D) and watered (W) treatments in each of the genotypes. Expression analysis across all the contrast groups revealed a total number of 3,330 significant differentially expressed (DE) genes [adjusted $p=<$ $0.01 ;>2$ fold change $\left(\log _{2} \mathrm{FC}>1\right)$ ]; 3,221 genes were regulated at the transcription level (DE), 314 genes were regulated by DAS (adjusted $p=<0.01 ;>10 \%$ change in alternative splicing) and 109 genes were regulated by both DE and DAS (Figure 5A). The $\mathrm{BD}-\mathrm{BW}$ contrast group showed the highest total of $\mathrm{DE}$ genes (1,203 up-regulated and 786 down-regulated), and OD$\mathrm{BD}$ showed the lowest number of DE genes (396 up-regulated and 292 down-regulated), indicating that Baronesse showed the 


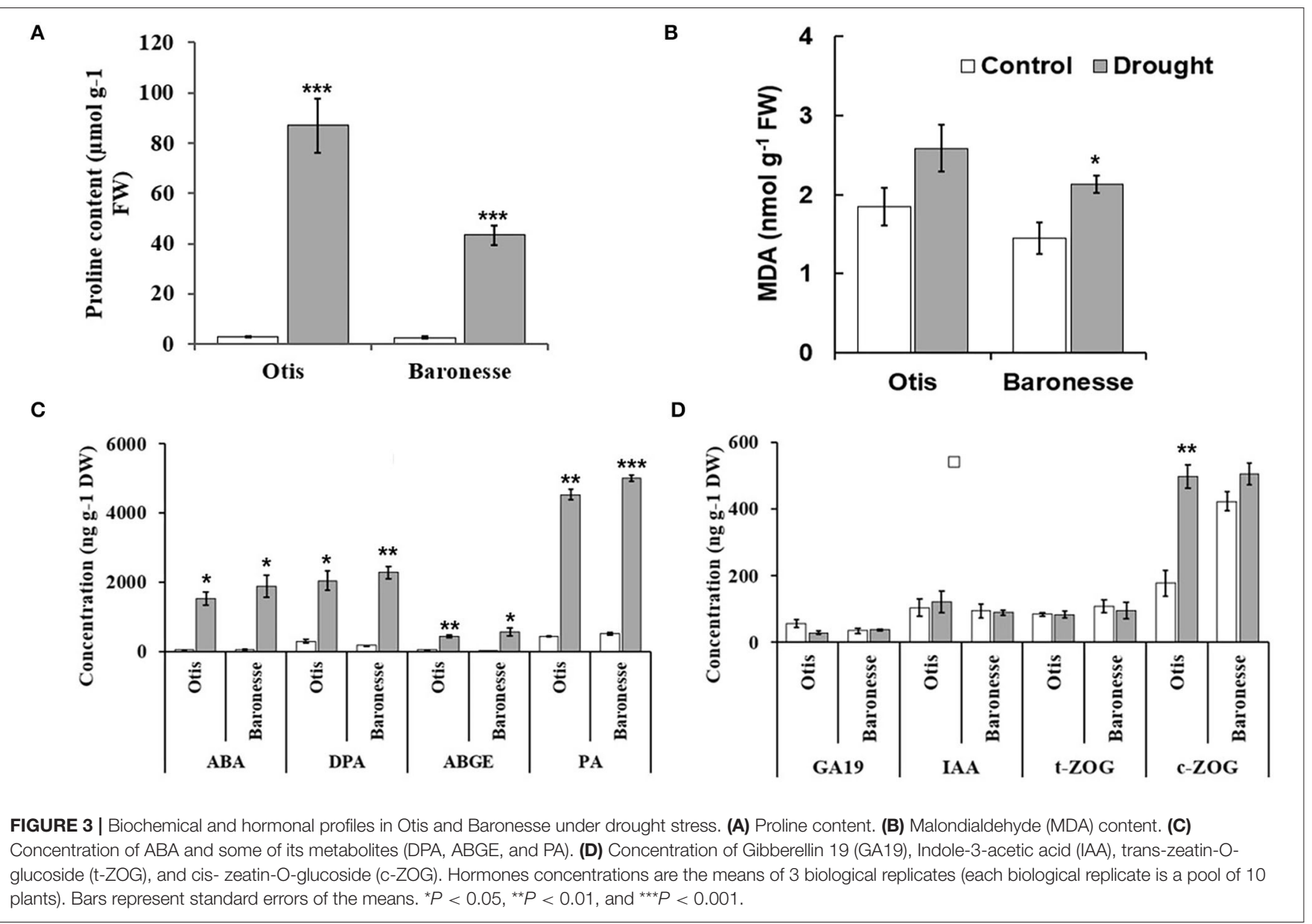

greatest transcriptional response to 5 days of drought. Some genes showed a similar up (286 genes) and downregulated (171 genes) expression response in both genotypes to the water deprived conditions (Table 1; Figure 5B). However, both genotypes responded differently to the drought conditions and there were 675 Baronesse genes and 126 Otis genes that were uniquely regulated in each genotype contributing to a different response by these two genotypes to the condition (Figures 5C,D). In addition, each genotype showed differentially expressed genes despite application of the condition (contrast groups OWBW and OD-BD). These gene expression differences highlight common responses to the deprived water condition but also show that these genotypes differ substantially from each other, which supports the morphological and physiological variation found. Supplementary Tables 2-7 show the detailed results of RNA Seq and gene expression.

\section{Differentially Expressed Genes in Otis and Baronesse Under Drought}

The categories of genes enriched in response to water deprivation were determined by performing a GO-enrichment analysis. The top three functional groups that were enriched in the common up-regulated genes between Otis and Baronesse were: response to water deprivation (GO:0009414), cation binding (GO:0043169), and raffinose alpha-galactosidase activity (GO:0052692) (Table 2). The unique up-regulated genes in Otis showed no significantly enriched processes. Whereas, the unique up-regulated genes of Baronesse were significantly enriched for cytosolic part (GO:0044445) and structural constituent of ribosome (GO:0003735) (Table 2).

The common down-regulated genes between the genotypes under water deprivation were found to be enriched for peptidyl-tyrosine modification (GO:0018212) (Table 2). The uniquely down-regulated genes of Otis (OD-OW) showed no significantly enriched processes. The top four processes that were enriched in the unique down-regulated genes of Baronesse (BDBW) are: protein phosphorylation (GO:0006468), ATP binding (GO:0005524), plasma membrane (GO:0005886), and protein kinase activity (GO:0004672).

The BARTV1.0 and HORVU annotations of the 21 genes under the GO term response to water deprivation (GO:0009414) are shown in Table 3. The common up-regulated genes showed known stress responsive genes such as chaperones, annexin, signaling genes (kinases and phosphatases), aquaporin, and transcription factors. The expression level of most of these genes in the drought treated plants of the two genotypes 


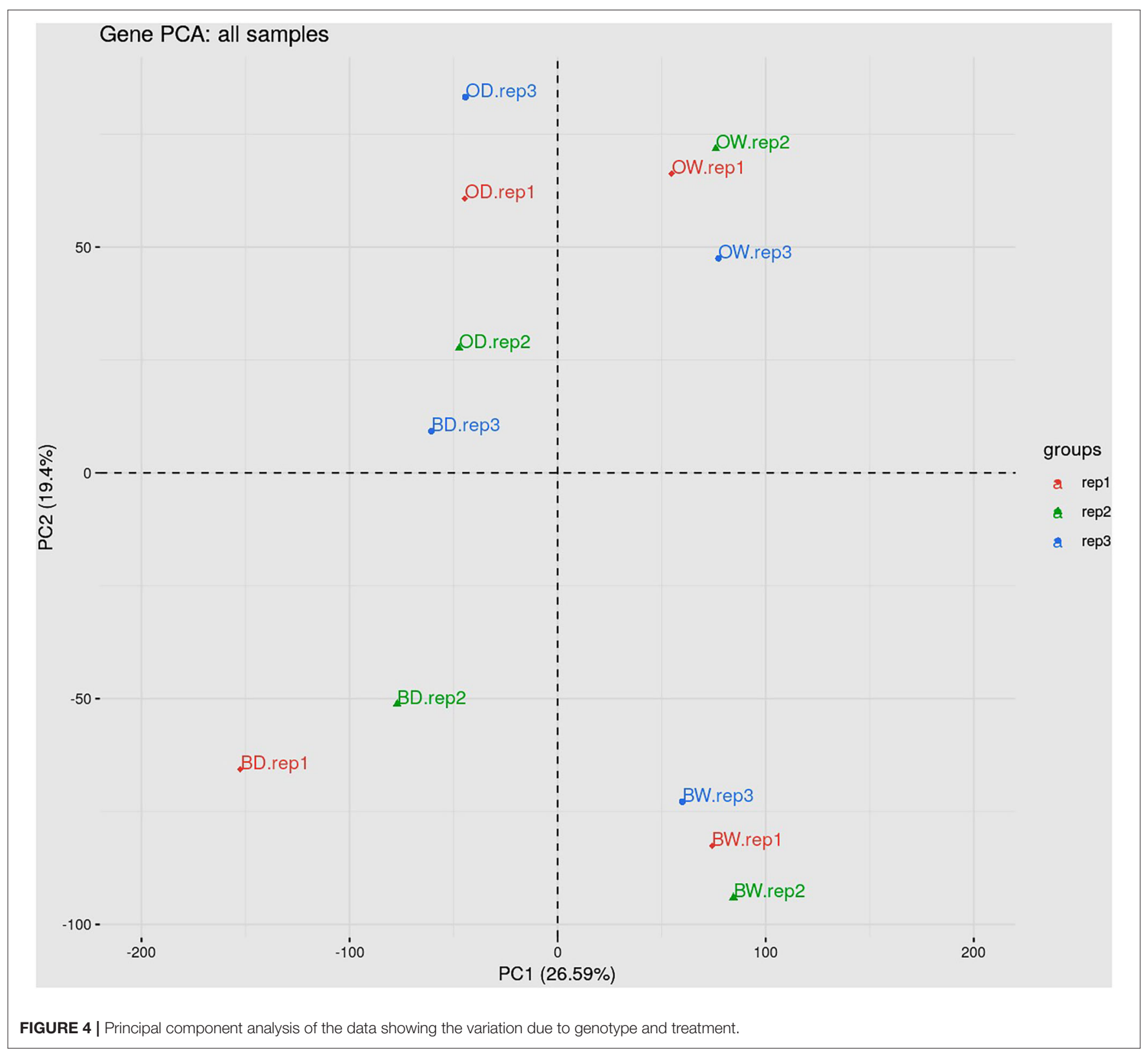

TABLE 1 | Number of genes that are regulated by differential expression and/or by differential alternative splicing (DAS) in the different contrast groups.

\begin{tabular}{lcccc}
\hline Contrast & DE genes & DE only & DE and DAS & DAS only \\
\hline OD-OW & 774 & 773 & 1 & 36 \\
BD-BW & 1,809 & 1,806 & 3 & 61 \\
OW-BW & 1,328 & 1,280 & 48 & 260 \\
OD-BD & 688 & 669 & 19 & 131 \\
\hline
\end{tabular}

is almost the same, except for a few genes. For example, the $\log _{2}$ FC of homeobox-leucine zipper protein ATHB-6 is 3.83 and 4.89 in the drought treated Otis and Baronesse plants, respectively. And the $\log _{2} \mathrm{FC}$ of betaine aldehyde dehydrogenase was 2.43 and 1.52 in the drought treated Otis and Baronesse, respectively.

The common down regulated genes between Otis and Baronesse were enriched for peptidyl-tyrosine modification (GO:0018212). Under this process 13 genes were down regulated under drought compared to the control. The BART and HORVU annotations of these genes are shown in Table 4. In general, the common-down regulated genes are groups of kinases such as cysteine-rich receptor like protein kinase 5, leucine-rich receptor-like protein kinase family protein isoform 2, and serine/threonine protein kinase. A number of these kinase genes show a much greater down-regulation in expression 


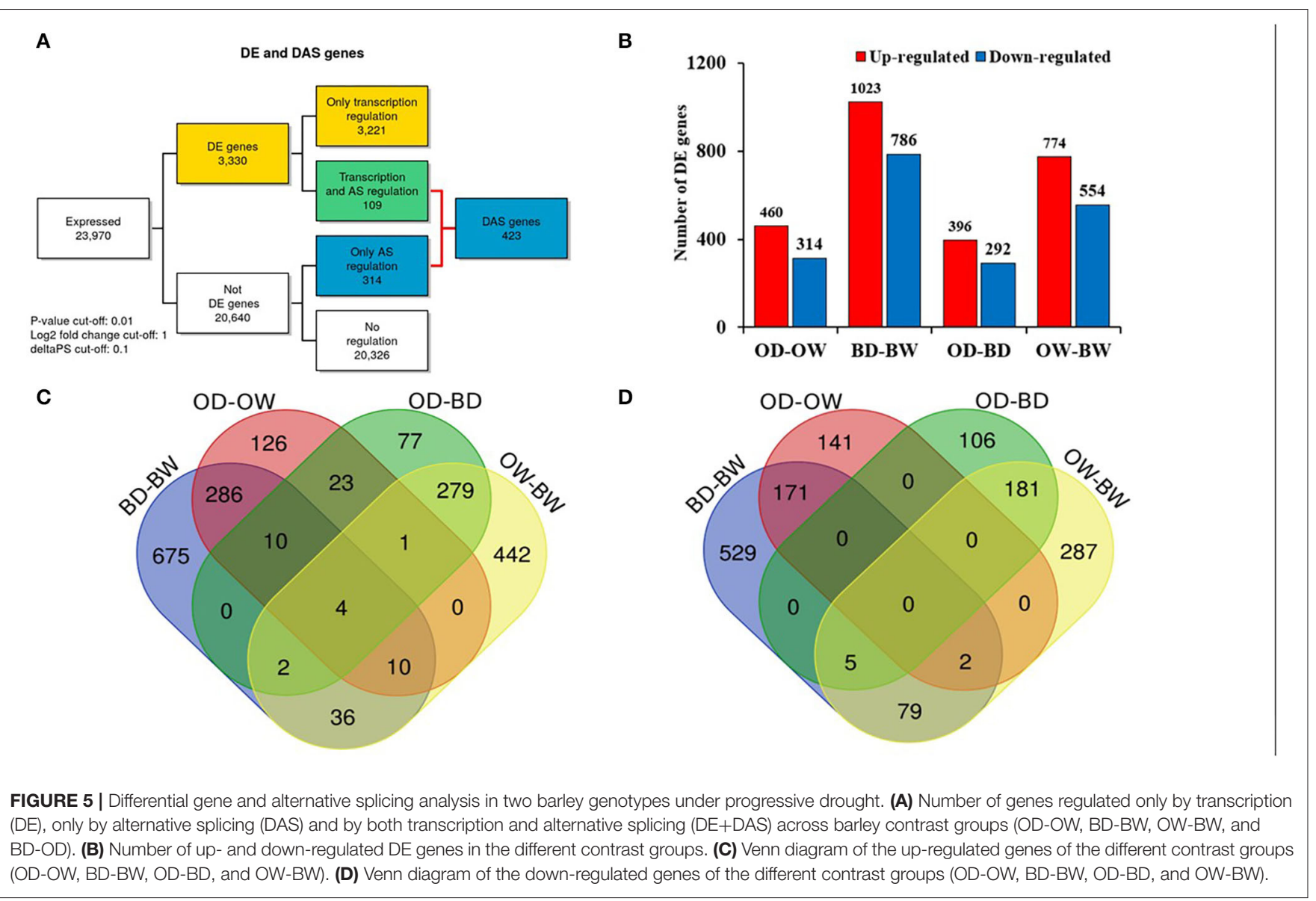

TABLE 2 | GO enrichment of the differentially expressed genes in Otis and Baronesse under drought compared to well-watered control (OD-OW and BD-BW).

Commonly up-regulated genes between Otis and Baronesse under drought (OD-OW and BD-BW)

\begin{tabular}{|c|c|c|c|c|c|}
\hline Term name & Term ID & Adjusted $P$-value & Term size & Query size & Intersection size \\
\hline Response to water deprivation & GO:0009414 & $1.42 \mathrm{E}-07$ & 399 & 240 & 21 \\
\hline Cation binding & GO:0043169 & 0.000373003 & 75 & 240 & 8 \\
\hline Raffinose alpha-galactosidase activity & GO:0052692 & 0.000416886 & 33 & 240 & 6 \\
\hline Metabolic process & GO:0008152 & 0.01750248 & 37 & 240 & 5 \\
\hline
\end{tabular}

Commonly down-regulated genes between Otis and Baronesse under drought (OD-OW and BD-BW)

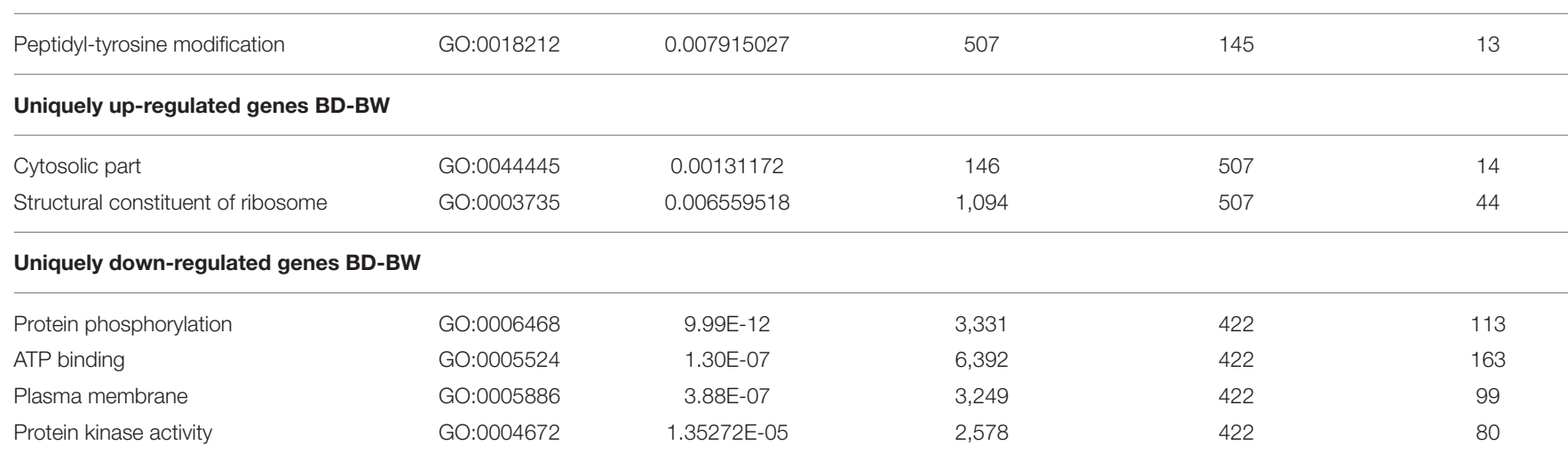


TABLE 3 | The BART and HORVU annotations of the commonly up-regulated genes under drought.

\begin{tabular}{|c|c|c|c|c|c|}
\hline BART gene ID & BART annotation & HORVU gene ID & HORVU annotation & $\begin{array}{l}\log _{2} F C \\
\text { OD-OW }\end{array}$ & $\begin{array}{l}\log _{2} \text { FC } \\
\text { BD-BW }\end{array}$ \\
\hline BART1_0-P29927 & $\begin{array}{l}\text { 2C-type protein } \\
\text { phosphatase protein }\end{array}$ & HORVU4Hr1G060370 & $\begin{array}{l}\text { Protein phosphatase } \\
2 \mathrm{C} \text { family protein }\end{array}$ & 3.41 & 3.33 \\
\hline BART1_0-P34164 & $\begin{array}{l}\text { Molecular chaperone } \\
\text { HtpG }\end{array}$ & HORVU5Hr1G027910 & $\begin{array}{l}\text { Chaperone protein } \\
\text { htpG family protein }\end{array}$ & 1.55 & 1.44 \\
\hline BART1_0-p07678 & Aquaporin protein & HORVU2Hr1G010990 & $\begin{array}{l}\text { Aquaporin-like } \\
\text { superfamily protein }\end{array}$ & 3.11 & 2.58 \\
\hline BART1_0-P51213 & $\begin{array}{l}\text { Low quality protein: } \\
\text { annexin D2 }\end{array}$ & HORVU7Hr1G037080 & Annexin 1 & 3.08 & 3.57 \\
\hline BART1_0-P39278 & $\begin{array}{l}\text { Cold-regulated plasma } \\
\text { membrane protein } 2\end{array}$ & HORVU5Hr1G098190 & $\begin{array}{l}\text { Cold acclimation } \\
\text { protein WCOR413 } \\
\text { family }\end{array}$ & 1.69 & 2.59 \\
\hline BART1_0-P07561 & $\begin{array}{l}\text { Putative ATP-binding } \\
\text { cassette subfamily C } \\
\text { member } 8\end{array}$ & HORVU2Hr1G009580 & $\begin{array}{l}\text { ABC transporter } C \\
\text { family member } 14\end{array}$ & 2.58 & 2.08 \\
\hline BART1_0-P45680 & $\begin{array}{l}\text { Homeobox-leucine } \\
\text { zipper protein ATHB-6 }\end{array}$ & HORVU6Hr1G061390 & $\begin{array}{l}\text { Homeobox-leucine } \\
\text { zipper protein family }\end{array}$ & 3.83 & 4.89 \\
\hline BART1_0-P36679 & $\begin{array}{l}\text { Non-specific } \\
\text { serine/threonine kinase } \\
\text { protein kinase }\end{array}$ & HORVU5Hr1G065350 & $\begin{array}{l}\text { Serine/threonine } \\
\text { protein kinase } 1\end{array}$ & 1.78 & 1.32 \\
\hline BART1_0-P35808 & $\begin{array}{l}\text { RNA recognition motif } \\
\text { domain }\end{array}$ & HORVU5Hr1G053230 & RNA-binding protein 1 & 1.32 & 1.17 \\
\hline BART1_0-P47576 & $\begin{array}{l}\text { Betaine aldehyde } \\
\text { dehydrogenase }\end{array}$ & HORVU2Hr1G070680 & $\begin{array}{l}\text { Betaine aldehyde } \\
\text { dehydrogenase } 2\end{array}$ & 2.43 & 1.52 \\
\hline BART1_0-P13794 & $\begin{array}{l}\text { Abscisic stress-ripening } \\
\text { protein } 2\end{array}$ & HORVU2Hr1G092710 & $\begin{array}{l}\text { Homeobox-leucine } \\
\text { zipper protein family }\end{array}$ & 3.17 & 1.75 \\
\hline BART1_0-P37103 & $\begin{array}{l}\text { Molecular chaperone } \\
\mathrm{HtpG}\end{array}$ & HORVU5Hr1G070720 & $\begin{array}{l}\text { Chaperone protein } \\
\text { htpG family protein }\end{array}$ & 1.65 & 1.79 \\
\hline BART1_0-P29183 & Sucrose synthase & HORVU4Hr1G049500 & Sucrose synthase 3 & 1.28 & 1.15 \\
\hline BART1_0-P29382 & Hexosyltransferase & HORVU4Hr1G052450 & Hexosyltransferase & 2.79 & 2.17 \\
\hline BART1_0-P21831 & $\begin{array}{l}\text { 2C-type protein } \\
\text { phosphatase protein }\end{array}$ & HORVU3Hr1G067380 & $\begin{array}{l}\text { Protein phosphatase } \\
2 \mathrm{C} \text { family protein }\end{array}$ & 2.98 & 3.27 \\
\hline BART1_0-P15058 & $\begin{array}{l}\text { Putative zeaxanthin } \\
\text { epoxidase }\end{array}$ & HORVU2Hr1G106880 & Chloroplastic lipocalin & 1.18 & 1.21 \\
\hline BART1_0-P29181 & Sucrose synthase & HORVU4Hr1G049500 & Sucrose synthase 3 & 2.03 & 2.02 \\
\hline
\end{tabular}

in Baronesse compared to Otis (Table 4). For example, the $\log _{2}$ FC of LRR receptor-like serine/threonine-protein kinase EFR (BART1_0-p15086) is -1.94 in Otis and -3.18 in Baronesse.

\section{The Most Highly Regulated Genes Under Drought in Genotype-Dependent Manner}

Differential gene expression analysis of the RNA-seq data identified highly induced or reduced genes as a response to drought. Both genotypes showed a different gene responding highly to the condition. In Otis, CER1 protein (BART1_0-p02677), Triticum beta-expansin (BART1_0p22302), multidrug/pheromone exporter, ABC superfamily (BART1_0-p46064), Armadillo (ARM) repeat superfamily protein (BART1_0-p34106), STAM-binding protein (BART1_0p13576), jasmonate induced protein (BART1_0-p25925), and NAC-type transcription factor (BART1_0-p58823) showed an expression level of $>5 \log _{2}$ FC. In Baronesse, the top 
TABLE 4 | The BART and HORVU annotations of the common down-regulated genes in barley plants under drought stress.

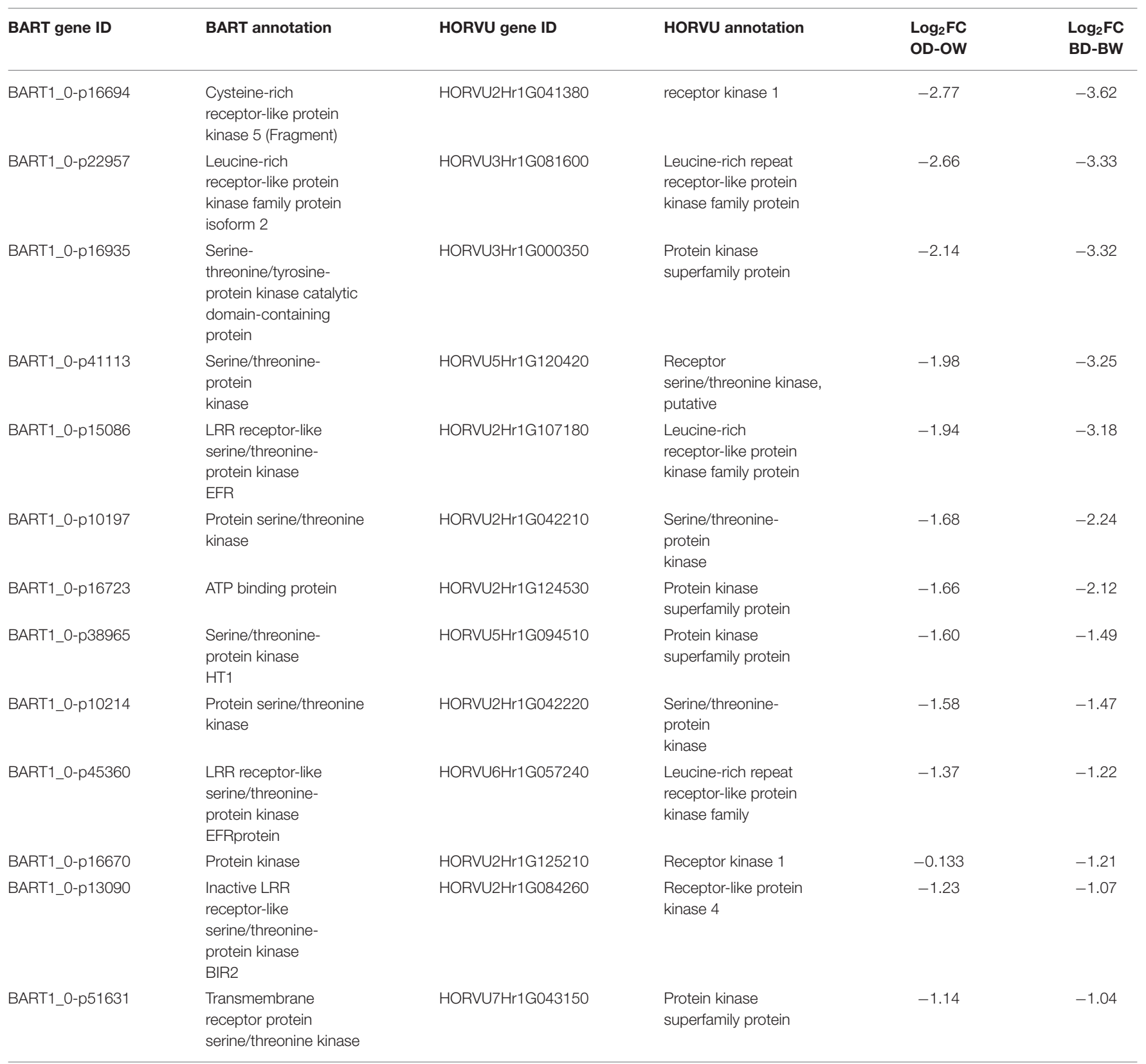

up-regulated genes with $\log _{2} \mathrm{FC}>7.5$ were: peptidyl-prolyl cis-trans isomerase (BART1_0-p44951), monooxygenase (BART1_0-p00176), late embryogenesis abundant proteinlike (BART1_0-p38756), dehydrin (BART1_0-p23589), late embryogenesis abundant (BART1_0-p47280), rRNA N-glycosylase (BART1_0-p31866), late embryogenesis abundant protein (BART1_0-p48484), and asparagine synthetase [glutamine-hydrolyzing] (BART1_0-p35535) (Supplementary Table 8).

The most significant down-regulated genes in Otis were catalytic genes such as NADPH-hemoprotein reductase (BART1_0-p22029), myrcene synthase, chloroplastic
(BART1_0-p56454), glucan endo-1,3-beta-glucosidase 13 (BART1_0-p06463), peroxidase (BART1_0-p08311), and Oacyltransferase WSD1 (BART1_0-p05934). In Baronesse, 6 of the most significant down-regulated genes were kinases such as L-type lectin-domain containing receptor kinase IX.1 (BART1_0-p48873), putative receptor protein kinase ZmPK1 (BART1_0-p21390), and Cysteine-rich receptor-like protein kinase 25 (BART1_0-p06472). Interestingly, aquaporin (BART1_0-p57239), transcription factor MYB4 (BART1_0p45446), and nicotianamine synthase (BART1_0-p47748) are among the most highly down-regulated genes in Baronesse (see Supplementary Table 9). 


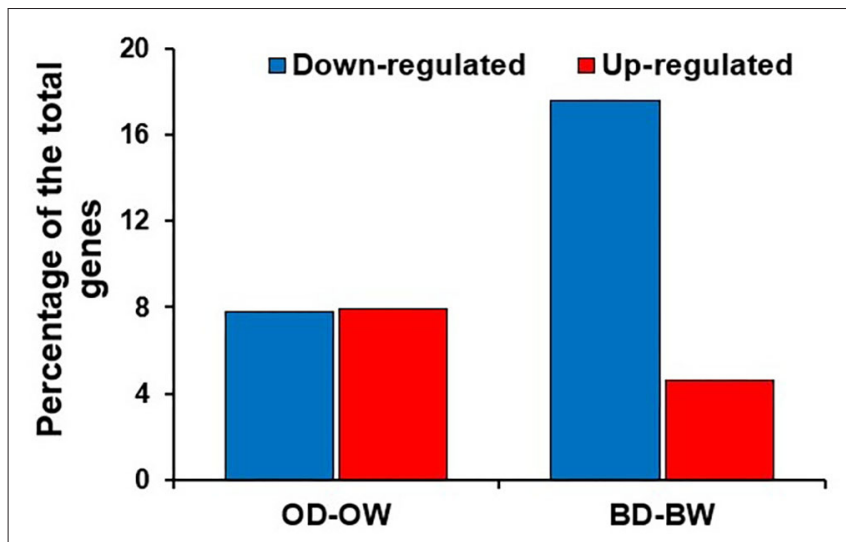

FIGURE 6 | Percentage of DEGs encoding kinases in Otis and Baronesse under drought.

\section{Photosynthesis Genes Were Repressed Under Drought}

The expression levels of several photosynthesis related genes were significantly down regulated in both the genotypes, indicating a general suppression of photosynthesis under drought. In drought-treated Otis, the expression level of photosystem II protein D1 (BART1_0-p16339), NAD(P)H-quinone oxidoreductase subunit 2, chloroplastic (BART1_0-p59777), ferredoxin-dependent glutamate synthase, chloroplastic-like (BART1_0-p10355), ATPase subunit IV (BART1_0-p59370), and proton-transporting ATP synthase activity (BART1_0p26862) were significantly downregulated. Likewise in Baronesse, the abundances of PSII protein D1 (Fragment) (BART1_0-p60027), PSII D2 protein (Fragment) (BART1_0p16337), NAD(P)H-quinone oxidoreductase subunit 2, chloroplastic (BART1_0-p44871), photosynthetic NDH subunit of subcomplex B (BART1_0-p46676), NADH-plastoquinone oxidoreductase subunit 5 (BART1_0-p03209), and ATP synthase CF1 alpha subunit, chloroplastic (BART1_0-p60215) were significantly down regulated under drought.

\section{The Differentially Expressed Kinases in the Two Genotypes Under Drought}

In plants, the kinases represent one of the largest category of genes which play significant roles in response to stress conditions. Differential gene expression analysis revealed that the kinases are the highest number of down-regulated genes in Baronesse under drought (Figure 6). Kinases account for 17.6 and $4.6 \%$ of down- and up-regulated genes in Baronesse, respectively, while the differentially regulated kinases represent $8 \%$ each for the upregulated and downregulated categories in Otis.

The DE kinases in the two genotypes are shown in Table 5; Supplementary Tables 10-13. In the down-regulated group of genes from Baronesse, the dominant family-subfamily was receptor like kinase-Pelle (RLK-Pelle). In this family/subfamily, 14 types of kinases were significantly down regulated more than 2-fold, including 10 RLK-Pelle-DLSV, 8 RLK-Pelle-WAK, 8 RLK-Pelle-L-LEC, and 7 RLK-Pelle-SD-2b. Baronesse also showed 7 RLK-Pelle genes up-regulated more than 2-fold. Otis showed 12 categories of kinases regulated under reduced water. For example, two $\mathrm{Ca} 2+/$ calmodulin-dependent protein kinases (CAMK) (OST1L and CAMKL-CHK1) were significantly down-regulated while CAMK-CAMKL-CHK1 was uniquely upregulated in Otis. In addition, two different categories of plant specific tyrosine kinase like (TLK) genes were significantly up regulated in the two genotypes under drought conditions.

\section{Differentially Expressed Transcription Factors in the Two Genotypes Under Drought}

Transcription factors (TFs) are key regulatory genes that coordinate regulation of plant development and conditional responses to a variety of stresses including drought. The number of differentially expressed TFs was higher in Baronesse (52 genes) compared to Otis (8 genes) (Supplementary Tables 14-17). In Otis, two bZIP and one NAC TFs were significantly downregulated while mainly NAC TFs were up-regulated. In Baronesse plants under drought stress, 4 out of 21 down-regulated TFs were WRKY, 3 MYB and 3 bZIP domain TFs were down-regulated too. The up-regulated TFs in drought-stressed Baronesse were 3 GATA, 2 NAC domain, 2 bZIP, 2 MYB, nuclear factor Y subunit B, PLATZ, trihelix, and ethylene-responsive transcription factor 5 TFs.

\section{Altered Expression of Chromatin Remodeling and Epigenetics-Associated Genes Under Drought}

Epigenetic mechanisms are involved in the plant's transcriptional response to environmental stresses such as drought. Baronesse showed the greatest transcriptional response to water depravation and showed regulation of chromatin remodeling genes. One histone methyl transferase (SET) (BART1_0-p53128) and 2 Snf2-family ATPases (SNF2 chromatin remodeler) (BART1_0-p18056, BART1_0-p51557) were significantly down regulated while two SET (BART1_0-p38488, and BART1_0p46523) and 1 GCN5-related N-terminal acetyltransferase (GNAT) (BART1_0-p31567) genes were up-regulated.

\section{Differential Alternative Splicing Under Drought Stress}

Serine and arginine-rich (SR) proteins are a group of highly conserved alternative splicing factors that have a role in regulating AS, changing the proportions of gene transcript isoforms under different plant stresses (Duque, 2011). Differential gene expression analysis identified barley orthologs of splicing factor RS31 (BART1_0-p31971; HORVU4Hr1G088790) and SC35-like splicing factor SCL30 (BART1_0-p26316; HORVU1Hr1G043200) genes that were up-regulated in response to water deprivation. RS31 showed a 2.7-fold increase in Otis and 3.6-fold in Baroness, while SCL30 showed a 1.7 -fold increase in Otis and 2.5-fold increase in Baronesse in response to the drought stress (Figure 7A). Gene expression analysis using the barley reference transcript dataset allowed quantification of individual transcript isoforms and 
TABLE 5 | The differentially expressed kinases in Otis and Baronesse under drought stress.

\begin{tabular}{|c|c|c|c|}
\hline OD-OW Down & OD-OW Up & BD-BW Down & BD-BW Up \\
\hline $\begin{array}{l}\text { CAMK } \\
\text { (Ca2+/calmodulin-dependent } \\
\text { protein kinase)_OST1L (Open } \\
\text { stomata-like kinase) }\end{array}$ & $\begin{array}{l}\text { CAMK_CDPK } \\
\text { (calcium-dependent protein } \\
\text { kinases) }\end{array}$ & CAMK_CAMKL-CHK1 & CAMK_CDPK \\
\hline $\begin{array}{l}\text { CAMK_CAMKL-CHK1 } \\
\text { (CAMK-Like, Checkpoint Kinase } \\
\text { 1) }\end{array}$ & CAMK_CAMKL-CHK1 & $\begin{array}{l}\text { WNK_NRBP [With No Lysine (K)' } \\
\text { kinases and nuclear receptor } \\
\text { binding protein (NRBP)] }\end{array}$ & RLK-Pelle_RLCK-VIla-1 \\
\hline $\begin{array}{l}\text { RLK-Pelle_RLCK-VIla-2 } \\
\text { (Receptor Like Cytoplasmic } \\
\text { Kinase-VIla-2) }\end{array}$ & CMGC_MAPK & $\begin{array}{l}\text { PEK_GCN2 (Pancreatic } \\
\text { eukaryotic initiation factor-2alpha } \\
\text { kinase, general control } \\
\text { non-derepressible) }\end{array}$ & RLK-Pelle_DLSV \\
\hline $\begin{array}{l}\text { RLK-Pelle_WAK (Wall Associated } \\
\text { Kinase) }\end{array}$ & $\begin{array}{l}\text { RLK-Pelle_DLSV (DUF26, SD-1, } \\
\text { LRR-VIII and WWA, a } \\
\text { moss-specific new RLK } \\
\text { subfamily) }\end{array}$ & $\begin{array}{l}\text { ULK_ULK4 (Unc-51 Like Kinase } \\
\text { 4) }\end{array}$ & $\begin{array}{l}\text { RLK-Pelle_CrRLK1L-1 } \\
\text { (Catharanthus roseus RLK1-like) }\end{array}$ \\
\hline \multirow[t]{11}{*}{$\begin{array}{l}\text { RLK-Pelle_LRR-XI-2 } \\
\text { (Leucine-rich repeat-XI-2) }\end{array}$} & RLK-Pelle_WAK & $\begin{array}{l}\text { NEK [Mitotic Kinase family, also } \\
\text { known as NRK (NimA-Related } \\
\text { Kinase, based on Aspergillus } \\
\text { NimA)] }\end{array}$ & RLK-Pelle_RLCK-Os \\
\hline & RLK-Pelle_LRR-V & RLK-Pelle_WAK & RLK-Pelle_RLCK-V \\
\hline & $\begin{array}{l}\text { TKL-PI-4 (Tyrosine kinase like } \\
\text { Plant-specific 4) }\end{array}$ & RLK-Pelle_SD-2b (S Domain 2b) & RLK-Pelle_L-LEC \\
\hline & & RLK-Pelle_LRR-Xa & $\begin{array}{l}\text { RLK-Pelle_PERK-1 (Plant } \\
\text { External Response Like Kinase 1) }\end{array}$ \\
\hline & & RLK-Pelle_LRR-VIII-1 & $\begin{array}{l}\text { TKL_Gdt (growth-differentiation } \\
\text { transition) }\end{array}$ \\
\hline & & RLK-Pelle_L-LEC (L-type lectin) & \\
\hline & & $\begin{array}{l}\text { RLK-Pelle_LRR-XII-1 } \\
\text { (Leucine-rich repeat-XII-1) }\end{array}$ & \\
\hline & & $\begin{array}{l}\text { RLK-Pelle_RLCK-Os (Receptor } \\
\text { Like Cytoplasmic Kinase-Os) }\end{array}$ & \\
\hline & & RLK-Pelle_LRR-Xb-1 & \\
\hline & & $\begin{array}{l}\text { RLK-Pelle_LRK10L-2 } \\
\text { (LRK10-like kinase type 2) }\end{array}$ & \\
\hline & & RLK-Pelle_DLSV & \\
\hline
\end{tabular}

to determine significant DAS events using the 3D RNA-seq App (Rapazote-Flores et al., 2019). To identify significant DAS genes, expression changes of a log2 fold change between gene transcripts were determined along with an adjusted $p<0.01$ and a minimum $0.1(10 \%)$ change in the proportion of spliced transcripts ( $\Delta$ Percent Spliced $-\Delta$ PS). Across the two genotypes under watered and drought conditions 423 genes were detected that showed significant changes in transcript isoforms across the different genotypes and conditions and 109 of these genes were regulated by both transcription and AS such that 314 genes were uniquely regulated by AS, with no overall significant change in gene expression (Figure 5A). Pair-wise comparisons of Otis and Baronesse's response to drought stress showed only 37 and 61 significant DAS genes, respectively, and only 6 genes were common between the two genotypes (Table 1; Supplementary Figure 2; Supplementary Tables 18-22). Of the 6 genes showing significant changes in AS in both genotypes, BART1_0-u33753 (HORVU5Hr1G021770) has similarity to unc93 homolog A, a positive regulator of abiotic stress tolerance in Arabidopsis (Xiang et al., 2018). This showed a complete reversal of the most abundant transcript BART1_0-u33753.005 in the watered samples of both genotypes to the BART1_0-u33753.001 transcript which was most abundant in drought samples (Figure 7B). This complete switch in transcript processing does not affect the protein coding sequence but results in the retention of an intron in the 3'UTR. GO enrichment analysis did not find any enrichment of GO terms, due to the broad range of different types of genes affected by AS genes and low number of AS genes found. These studies suggest that alternative splicing is less frequently affected under drought compared to other abiotic stresses. The results here also show genotype-specific differences in DAS responses under drought.

\section{Validation of the RNA-Seq Profiles Using RT-qPCR}

We used qRT-PCR and validated the gene expression profiles of several genes (Figure 8). For example, the cytokinin-oglucosyltransferase 2 (BART_0-p11824) was up-regulated under drought stress in both the genotypes (OD-OW and BDBW showed 1.69- and 1.30-fold change (RNA Seq) and 2.23 
A

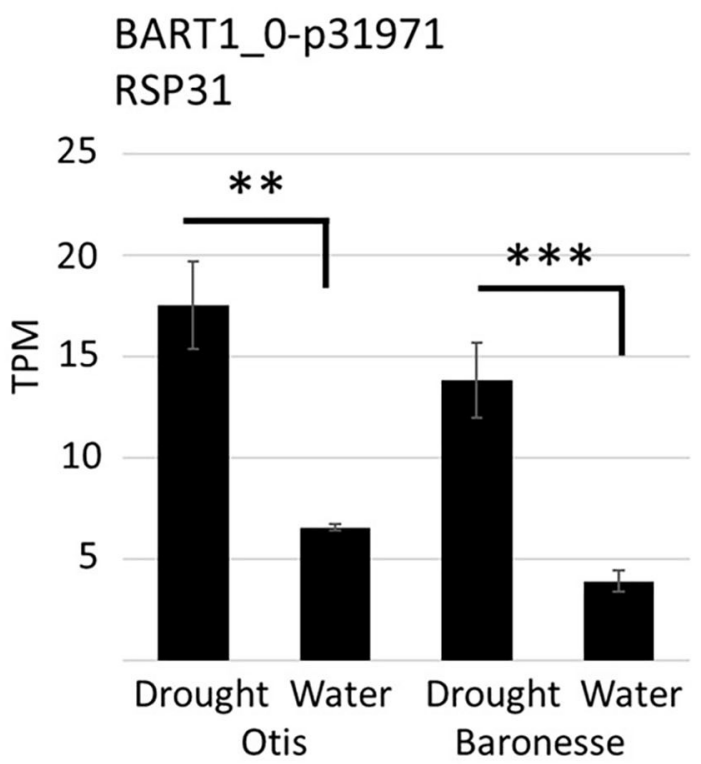

\section{BART1_0-p26316 \\ SCL30}

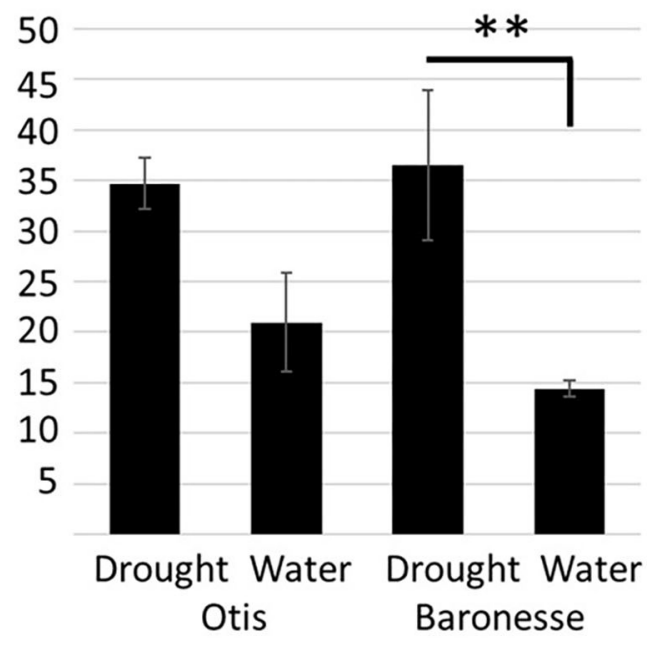

B

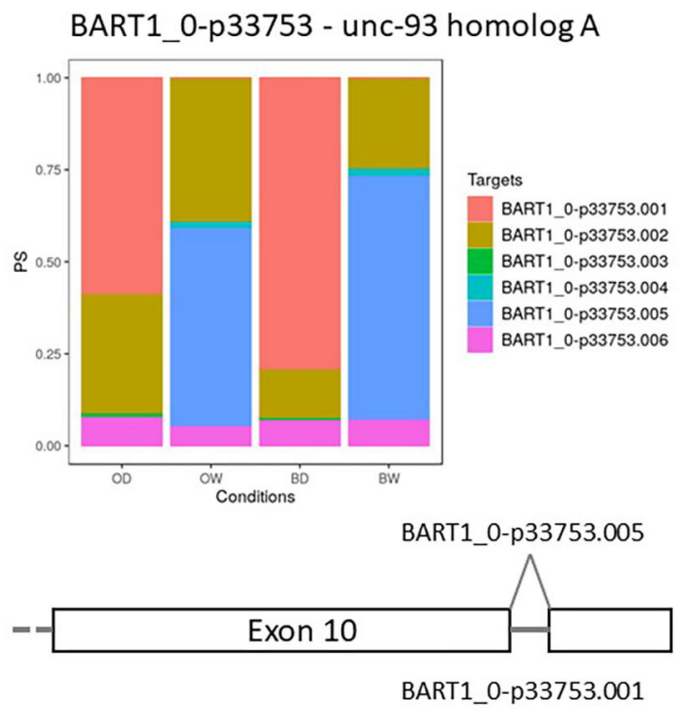

FIGURE 7 | Expression analysis of AS associated genes. (A) Mean differential gene expression of barley orthologs of SR splicing factors, RS31 and SCL30. Histograms show expression levels in transcripts per million (TPM) for watered and drought-treated Otis and Baronesse. Standard errors are the result of three biological repeats. Adjusted $p$ values on $\log _{2} \mathrm{FC}:{ }^{\star \star}<0.005$; ${ }^{\star \star \star}<0.001$. (B) Expression analysis of UNC93-A AS transcripts. Each gene transcript is represented by a different color. Each histogram bar represents an individual genotype under a specific condition. From left to right is Otis drought (OD), Otis watered (OW), Baronesse drought (BD) and Baronesse watered (BW).

and 6.81 (qPCR), respectively). Tryptophan aminotransferase related 2 (BART1_0-p18317) was down-regulated in Baronesse under drought (-2.67 (RNA Seq) and 0.24-fold change (qPCR). Cellulose synthase was downregulated in Otis plants under control conditions compared to Baronesse plants [-2.99 (RNA Seq) and-19.87 (qPCR]. But it was up regulated in Otis under drought stress compared to Baronesse. Phenylalanine ammonia lyase was down-regulated in Otis plants under control conditions 

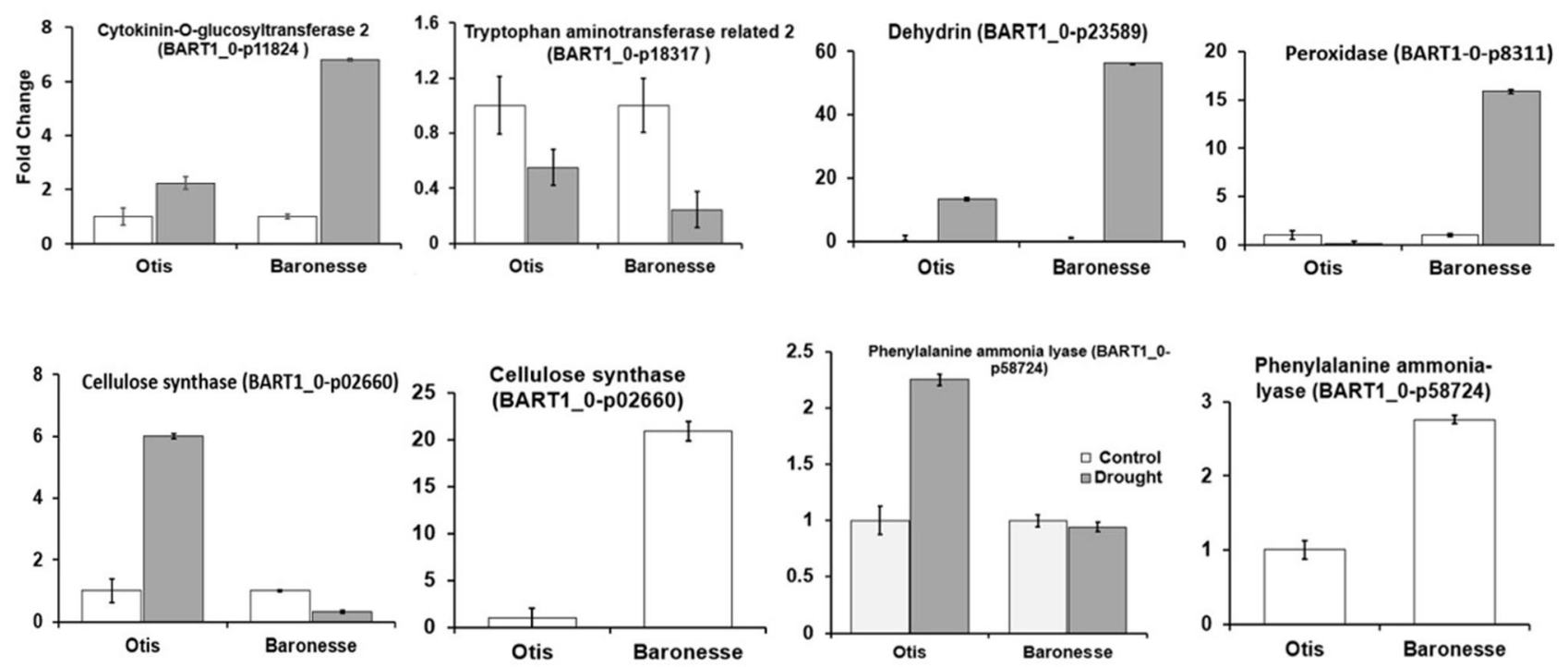

FIGURE 8 | Quantitative real-time PCR validation of RNA-seq data for selected genes.

compared to Baronesse plants [-1.16 (RNA Seq) and -1.76 (qPCR)]. But it was up regulated in Otis under drought stress compared to Baronesse.

\section{DISCUSSION}

When compared with Otis, Baronesse was found to be more sensitive to drought as revealed by the biomass, leaf relative water content, proline accumulation, and the parameters associated with photosynthesis. Although significant decrease in the net photosynthetic rate $(\mathrm{PN})$, stomatal conductance (gs), and the transpiration rate (E) was observed in both the barley genotypes under drought, but the degree of inhibition was less in the Otis compared to Baronesse. Indeed, this difference between the genotypes was supported by the RNA-Seq analysis that revealed a greater down regulation of several photosynthesis-related genes (genes for D1 protein (PsbA) and D2 protein (PsbD) in Baronesse compared to Otis. PSII (both D1 and D2 proteins are needed for assembly of a stable PSII complex) plays an important role in response to environmental stresses (Baker, 1991). In wheat genotypes, drought resulted in different degrees of repression of PsbA and PsbD genes, however, less repression of both genes (especially the PsbD gene) in the drought tolerant genotype (Liu et al., 2006).

Under well-watered conditions, Otis plants showed significantly less gs and $\mathrm{E}$ than Baronesse. This suggests that Otis might have lower stomatal density compared to Baronesse, which could be one player in drought tolerance of Otis. In line with this, the overexpression of epidermal patterning factor (EPF) (HvEPF1) in barley resulted in a significant reduction in stomatal density without adverse effects on the normal growth of the overexpression lines (Hughes et al., 2017). In addition, the overexpression lines showed less gs than the wild type under wellwatered conditions. And under drought stress, they have higher water use efficiency and drought tolerance compared to the wild type. In drought tolerant rice and wheat genotypes, transpiration efficiency (TE) was enhanced by maximizing mesophyll conductance $(\mathrm{gm})$ and minimizing stomatal conductance (gs) (Ouyang et al., 2017). Indeed, the drought tolerant rice and wheat showed low stomatal density, and thick mesophyll with thin cell walls.

\section{Correlations Between the Gene Expression Profiles of Proline and Glycine Betaine and Their Accumulation and Relative Water Content}

Proline content was increased in both genotypes under drought, but the increase was significantly higher in Otis plants. Proline is an imino acid that acts as an osmoprotectant, a metal chelator, an antioxidative molecule, and a signaling molecule that enhances drought tolerance by maintaining the osmotic balance of the cells (Blum, 2009; Hayat et al., 2012). The LRWC of the two genotypes was significantly reduced, but drought treated Otis plants showed less reduction in their LRWC (Figure 2A). This response highlights one aspect of several mechanisms that could be used by Otis to tolerate drought better compared to Baronesse. High proline accumulation in the leaves of barley plants under severe osmotic stress leads to less membrane injury (Bandurska, 2001). In wild barley high proline accumulation in the leaves increased drought tolerance compared to cultivated barley (Bandurska and Stroihski, 2003). Indeed, in many major crop plants such as wheat, barley, and maize, osmotic adjustment was positively correlated with stress resistance (Blum, 2017). The expression of proline biosynthesis and turnover genes reflect this enhanced production of proline in both genotypes under drought. Pyrroline-5-carboxylate 
synthase (P5CS), pyrroline-5-carboxylate reductase, pyrroline5 -carboxylate dehydrogenase and Orn- $\delta$-aminotransferase were all significantly induced in drought conditions. Only the proline turnover gene proline dehydrogenase expression was reduced under drought conditions. Although differences between the genotypes were not significant under reduced water conditions, the trend showed larger levels of expression in Otis (Supplementary Figure 1).

Glycine betaine (GB) is another important osmolyte and is known to accumulate in response to abiotic stresses in a variety of plant species (Ashraf and Foolad, 2007). GB is produced from choline via choline monooxygenase (CMO) and betaine aldehyde dehydrogenase $(\mathrm{BADH})$. In barley, BADH1 and $\mathrm{BADH} 2$ genes were significantly induced under drought and salinity (Nakamura et al., 2001). Our results reveal that BADH (BART1_0-p47576, HORVU2Hr1G070680) was induced in both genotypes under drought. However, its expression was higher in Otis compared to Baronesse.

\section{Hormonal Profiles}

Among the hormones, ABA is the most important hormone regarding its role in plant drought tolerance (DaszkowskaGolec, 2016; Sah et al., 2016; Vishwakarma et al., 2017). In this study, both genotypes accumulated ABA as well as several ABA-related metabolites under drought but the accumulation levels did not differ greatly between the genotypes. Likewise, the response of auxin levels was hardly differed between the genotypes under drought.

Cytokinins (CKs) and their metabolism is important in plants' adaptation to different abiotic stresses including drought (Ha et al., 2012; Pavlu et al., 2018). Drought stress caused a significant increase in the cytokinin, cZOG in Otis compared to Baronesse, suggesting a potential role for $\mathrm{CZOG}$ in the drought tolerance. Conjugation of $\mathrm{O}$-glucose to $\mathrm{cZ} \mathrm{CKs}(\mathrm{O}$ glucosylation) results in the formation of O-glucosides, and it is a reversible modification and the $\mathrm{O}$-glucosides such as cZOG are storage forms of cZ CKs (Schäfer et al., 2015). A role for cis-Zeatin (cZ) CKs in plant growth and development has been reported (Kudo et al., 2012; Schäfer et al., 2015). It was also suggested that $\mathrm{cZ}$ CKs could be important for maintaining minimum $\mathrm{CK}$ activity for cell survival under stress conditions (Gajdošová et al., 2011).

With over 100 identified GAs, only a few are bioactive: GA1, GA3, and GA4 (Yamaguchi, 2008). The levels of GAs were found to be decreased under drought stress, and this could be associated with the retarded plant growth under stress (Nelissen et al., 2018). In small cereals (Tef and finger millet), the inhibition of GA biosynthesis resulted in an enhanced tolerance to osmotic stress (Plaza-Wüthrich et al., 2016). It was further reported that the reduction of GAs enhanced drought tolerance by osmotic adjustment and maintenance of leaf turgor of tomato (Omena-Garcia et al., 2019). Remarkably, GA20 levels were only increased in the drought-treated Otis. GA20 is an intermediate of GA1 and GA3, which is converted to GA1 by GA 3oxidase (GA3ox) (Yamaguchi, 2008). This conversion was shown to be inhibited by heat, dehydration, and salinity (Colebrook et al., 2014). The increase in GA20 in the drought-treated Otis suggests a less conversion of this gibberellin to the bioactive forms of GA.

For hormonal profiling, samples of barley leaves were taken at the initial wilting stage of drought ( 5 days of drought). At this stage, no significant changes were observed for shoot length or biomass in the two genotypes under drought stress compared to the control. This might explain the observed small number of differences regarding hormonal profiles under drought in the genotypes.

\section{General Transcriptional Responses Greatly Differed Between the Genotypes}

The drought sensitive genotype Baronesse showed higher number of differentially expressed genes (DEGs) under drought (1,023, and 786 up and down-regulated, respectively), compared to Otis (460, and 314 up and down-regulated genes, respectively), in the drought-tolerant Otis indicating that the transcriptional changes were far greater in sensitive genotype. Indeed, previous studies have reported a greater number of stress-regulated genes in the sensitive genotypes compared to the tolerant genotypes subjected to stress treatments (Silveira et al., 2015; Cantalapiedra et al., 2017; Janiak et al., 2019; Ereful et al., 2020).

\section{The Shared Responses Between Otis and Baronesse as Revealed by the Differentially Expressed Genes}

In this study, several differentially regulated genes (signaling genes (kinases and phosphatases), transcription factors, chaperones, annexins, and aquaporins) that showed almost similar level of regulation in both the genotypes under drought have been identified and these could be important for maintaining cellular homeostasis under stress.

Chaperones have been shown to stabilize membranes and proteins by assisting with folding, association, translocation, and degradation of proteins under stress (Priya et al., 2019). The chaperone gene BART1_0-p34164 (HORVU5Hr1G027910) was up regulated in the drought-treated Otis and Baronesse (Log2 FC is 1.55 and 1.44, respectively). The ortholog of this gene in Arabidopsis was shown to be induced under drought stress (Gupta and Senthil-Kuma, 2017).

Aquaporins (AQPs) are pore forming proteins belonging to the major intrinsic proteins (MIP) superfamily which transport water and other small neutral compounds across the membrane. The upregulation of AQPs in response to abiotic stresses is known in plants (Quigley et al., 2001; Scharwies, 2017; Kapilan et al., 2018). The aquaporin, BART1_0-p07678, HORVU2Hr1G010990 was significantly induced in both the genotypes under drought stress. The rice ortholog (OsPIP2.6) of this gene (LOC_Os04g16450), has shown to be induced in the drought tolerant parent and the inbred lines but repressed in the drought sensitive parent (Baghyalakshmi et al., 2020).

Annexins are a diverse, multigene family of calciumdependent, membrane-binding proteins that serve as targets for 
$\mathrm{Ca} 2+$ in most eukaryotic cells (Clark et al., 2001). An annexin gene (BART1_0-p51213, HORVU7Hr1G037080) was one among the commonly up regulated genes in Otis and Baronesse under drought stress (Log2 $\mathrm{FC}$ is 3.08 and 3.57, respectively). The orthologous gene in rice (LOC_Os06g11800) was shown to be upregulated under drought stress (Gorantla et al., 2005). The Arabidopsis ortholog of Annexin 1 (AT1G35720) was also induced by drought and its overexpression confers enhanced drought tolerance (Konopka-Postupolska et al., 2009). A possible mode of Annexin 1 in drought tolerance include the alleviation of the oxidation of the membrane's lipids and proteins (Jami et al., 2008).

\section{A Gene for Wax Biosynthesis was Uniquely and Highly Induced in Otis Genotype Under Drought}

ECERIFERUM1 (CER1) gene [CER1 from fatty acid hydrolase superfamily (BART1_0-p02677)] involved in wax biosynthesis was highly upregulated in Otis under drought. The Arabidopsis and rice orthologs of this gene are CER1 (AT1G02205) and WAX2 (LOC_Os10g33250), respectively. In drought treated Arabidopsis plants, the expression of CER1 gene was up regulated, along with a significant increase in the very long chain (VLC) alkanes in the cuticle (Kosma et al., 2009). The Arabidopsis CER1 gene codes for an important enzyme involved in the biosynthesis of VLC alkanes of the cuticle (Bourdenx et al., 2011). The cuticle is a hydrocarbon epidermal extension, that acts as a protective barrier against water loss under drought stress. Indeed, the overexpression of CER1 in Arabidopsis conferred drought tolerance due to reduced water loss (Bourdenx et al., 2011). In Brachypodium, eight homologs of CER1 were identified (Wu et al., 2019). BdCER1-8 was highly expressed in the leaves, and it was significantly induced by drought and osmotic stress. Moreover, BdCER1-8 rescued the biosynthesis of the VLC alkanes in cer1 Arabidopsis mutant (Wu et al., 2009). The overexpression of the transcription factor TaSHN1 in wheat resulted in reduced stomatal density and leaf water loss, and thereby improved drought tolerance of the transgenic lines (Bi et al., 2018). In addition, the analysis of the cuticle composition of TaSHN1overexpression lines revealed a significant increase in the alkanes under control and drought conditions. The overexpression of TaSHN1 also resulted in more than 10-fold upregulation of the cuticle biosynthetic genes such as: ATT1/CYP86, CER4-6, KCS1, and LACS3. This indicates that one mechanism of the improved drought tolerance in the TaSHN1 overexpression lines is through changes in the cuticle composition both at the molecular and biochemical levels. The induction of CER1 in the drought-treated Otis is one of the few major differences of supporting drought tolerant nature of Otis compared to Baronesse. This might explain the less reduction in the leaf relative water content in Otis under drought stress. Indeed, a detailed analysis of the cuticle composition of Otis and Baronesse under drought and control conditions will shed more light on drought tolerance in barley.

\section{A Beta-Expansin Gene was Uniquely and Highly Induced in Otis Genotype Under Drought}

Expansin gene family is one group of cell wall modifying genes (Cosgrove, 2000). Expansin genes are important players in cell growth through loosening of the cell wall (Cosgrove, 2015). Phylogenetically, expansin genes are divided into two major families: EXPA ( $\alpha$-expansins) and EXPB ( $\beta$-expansins) (Cosgrove, 2015). In barley, a total of 34 expansin genes (14 EXPA, 17 EXPB, and 3 EXPLA) were identified (Lombardi, 2012). The expression of the barley expansin genes showed specific expression profile for each tissue, organ, and developmental stage. Previous studies showed the involvement of expansin genes in many growth and developmental processes (Choi et al., 2003; Marowa et al., 2016). Moreover, expansin genes were found to be differentially expressed under different abiotic stresses (Wu et al., 2001; Bray, 2004; Harb et al., 2010; Marowa et al., 2016). The overexpression of TaEXPA2 in tobacco and wheat enhanced drought tolerance in the transgenic plants (Chen et al., 2016; Yang et al., 2020). Moreover, improved tolerance to salinity and drought was also shown in tobacco plants overexpressing the tobacco EXPA4 (Chen et al., 2018). In barley, HvEXPB7 improved the growth of barley root hairs under drought in the drought tolerant Tibetan wild barley genotype (He et al., 2015). The beta expansin gene (BART1_0-p22302) was highly induced in the drought stressed Otis ( $\log 2$ FC is 6). The Arabidopsis and rice orthologs of this gene are AT1G65680 (AtEXPB2), and LOC_Os03g01270 (OsEXPB7). The rice gene was significantly repressed under dehydration conditions (Zhou et al., 2007; Ray et al., 2011; Shaik and Ramakrishna, 2012). In these studies, the changes in gene expression were tested in one genotype of rice under dehydration stress, which is considered as a shock stress to plants. Whereas, in this study, two barley genotypes with contrasting drought tolerance were exposed to progressive drought for 5 days. Indeed, a low correlation between gene expression under dehydration shock and that under progressive (gradual) drought was shown in barley (Talamé et al., 2007).

\section{An Armadillo (ARM) Repeat Gene is Highly Upregulated in Otis Genotype Under Drought}

Armadillo (ARM) repeat gene family has the ARM repeat domain, which is composed of one short and two relatively longer $\alpha$-helices (Mudgil et al., 2004; Sharma and Pandey, 2016). It includes members of diverse functions such as: signal transduction, nuclear transport, cell adhesion, and protein degradation (Sharma et al., 2014). The most common protein arrangement of ARM family is U-box/ARM (PUB/ARM), which suggests a role in protein ubiquitination (Sharma and Pandey, 2016). This will result in higher plasticity in response to the changing environments. The Armadillo gene was among the drought responsive genes in the drought tolerant potato genotype (Pieczynski et al., 2018). In rice plants, 36 OsARM genes were differentially expressed under different abiotic stresses (drought, salt, and cold) (26 up-regulated and 10 down-regulated) (Sharma et al., 2014). Out of the 26 up-regulated genes 7 were uniquely 
drought induced genes, and 4 out of 10 were uniquely drought repressed genes. In barley, $5 \mathrm{PUB} / \mathrm{ARM}$ genes [class II U-box E3 ubiquitin ligases (HvPUB7, HvPUB9, HvPUB15, HvPUB16, HvPUB21, and HvPUB22)] were significantly induced, and one gene (HvPUB18) was repressed under dehydration stress (Ryu et al., 2019). The ARM repeat gene (BART1_0-p34106) was highly induced in Otis drought stressed plants ( $\log 2$ FC 5.88). This gene is not a member of the U-box E3 ubiquitin ligase family in barley (Ryu et al., 2019). This suggests that it might function in drought tolerance of Otis via mechanism (s) other than protein ubiquitination and degradation.

\section{Kinases are Predominantly Down Regulated in Baronesse Plants Under Drought}

Genes encoding protein kinases (Pks) were overrepresented among the down regulated genes in drought-treated Baronesse. Most of these kinases are receptor like kinase-Pelle (RLKPelle). Receptor like kinase-Pelle is the largest gene family in Arabidopsis and rice, which are responsive to different abiotic and biotic stresses (Lehti-Shiu et al., 2009). In rice, receptor-like cytoplasmic kinase GROWTH UNDER DROUGHT KINASE (GUDK) was shown to improve drought tolerance through the activation of the transcription factor APETALA2/ETHYLENE RESPONSE FACTOR OsAP37 (Ramegowda et al., 2014). The overexpression of poplar leucine-rich repeat (LRR) receptorlike kinase in Arabidopsis enhanced water use efficiency (Xing et al., 2011). The general down regulation of many kinases in Baronesse relative to Otis could be one of the factors associated with drought sensitivity.

\section{Transcription Factors}

Transcription factors (TFs) are regulatory proteins that play an important role in almost all plant processes including adaptation to biotic and abiotic stresses (Nakashima et al., 2014; Joshi et al., 2016). TF genes such as AP2/EREBP, bZIP, MYB/MYC, NAC, WRKY have been implicated in drought stress responses (Gahluat et al., 2016). The number of DEGs encoding TFs were more in the drought-stressed Baronesse than in Otis.

NAC genes are plant-specific transcription factors involved in growth and development and stress responses. Overexpression of several NAC genes from Arabidopsis, rice, and soybean increased the tolerance of transgenic plants to abiotic stresses including drought (Nakashima et al., 2007; Hao et al., 2011; Wang and Dane, 2013; Shim et al., 2018). In drought stressed Otis, two NAC genes were up regulated, while one NAC gene was down regulated. The overexpression of wheat NAC TF improved tolerance to drought and salt stress in Arabidopsis (Huang et al., 2015).

One of the induced NAC genes in Otis genotype is BART1_0p58823 (HORVU0Hr1G017490), which has Log2FC of 5.33. The rice ortholog of this gene is LOC_Os02g56600, which was induced in the salt-tolerant rice genotype but repressed in the salt-sensitive genotype (García-Morales et al., 2014). The other NAC gene that was induced specifically in the Otis genotype is BART1_0-p12809 (HORVU2Hr1G080460), which has $\log 2 \mathrm{FC}$ of 2.95. The ortholog of this gene in rice is LOC_Os04g38720 (OsNAC2), which was also induced by salt stress (Narsai et al., 2013). The one NAC gene that was uniquely repressed (Log2FC of-2.09) in Otis under drought is BART1_0p22840 (HORVU3Hr1G080100). The rice ortholog of this gene is OsNAC4 (LOC_Os01g60020), which was induced in the dehydrated wild rice (Oryza rufipogon) (Zhang et al., 2017). Another study showed this gene was highly induced in the drought tolerant rice genotype than the sensitive genotype after 3 hours of dehydration (Borah et al., 2017). In the two previous studies, rice plants were exposed to a dehydration shock rather than a progressive drought treatment.

The rice ortholog of BART1_0-p13794 gene is OsHOX22 (LOC_Os04g45810), which was induced by desiccation, salinity, cold, and osmotic stresses (Bhattacharjee et al., 2016). Moreover, it was among the drought expressed genes in rice in the co-expression analysis of different transcriptome datasets $(\mathrm{Lv}$ et al., 2019). The expression level of this gene greatly differed between Otis and Baronesse (3.17 and 1.75 Log2FC, Otis and Baronesse, respectively). The higher induction of this gene in Otis might be important for drought tolerance in this genotype.

Tryptophan-arginine-tyrosine (WRKY) proteins are one of the largest families of transcription factors specific to plants (Zhang and Wang, 2005). Many WRKY genes have been shown to be induced by abiotic stresses including drought (Chen et al., 2011). Their overexpression resulted in improved drought tolerance in different plant species ( $\mathrm{Wu}$ et al., 2009; Cai et al., 2014; Xu et al., 2014; Ding et al., 2016). In this study, 4 out of the 21 drought-repressed TFs in the Baronesse plants were WRKY TFs with $\log 2 \mathrm{FC} \leq-2$. These WRKY genes are: BART1_0-p09203 (HORVU2Hr1G029450), BART1_0-p23505 (HORVU3Hr1G088200), BART1_0p01968 (HORVU1Hr1G027700), and BART1_0-p21247 (HORVU3Hr1G059210) with Log2FC-3.22,-2.31,-2.82, and-2.95, respectively. The rice orthologs of these genes are: OsWRKY69 (LOC_Os08g29660), OsWRKY24 (LOC_Os01g61080), OsWRKY67 (LOC_Os05g09020), and OsWRKY15 (LOC_Os01g46800). OsWRKY69 was up regulated in the leaves and root of drought tolerant rice genotype (Silveira et al., 2015; Baldoni et al., 2016). Whereas, OsWRKY24, OsWRKY67, and OsWRKY15 were found to play a role in tolerance of phosphorus deficiency, bacterial resistance, and cold tolerance, respectively (Yang et al., 2015; Deng et al., 2018; Liu Q. et al., 2018).

\section{Alternative Splicing}

Alternative splicing (AS) is an important posttranscriptional mechanism in which different combinations of exons of a primary transcript are joined to produce diverse messenger RNA (mRNA) isoforms. Interestingly, the abiotic stresses were shown to alter the AS pattern in plants (Reddy et al., 2013; Laloum et al., 2018). In this study only a relatively small number of AS genes (37 genes in Otis and 61 genes in Baronesse) were identified in barley genotypes exposed to drought (Table 1). It was reported previously that the DAS events were relatively smaller under drought compared to other abiotic stresses. For example, in 
wheat, only 200 genes undergoing DAS under drought while this number is rather high (3,576 genes) under heat stress (Liu Z. et al., 2018). In Cassava, only 1,025 genes showed DAS in response to drought stress compared to 3,292 genes in response to cold stress (Li et al., 2020). In maize, 1,045 and 985 genes showed DAS under heat and cold stresses, respectively, while only 281 and 204 genes showed DAS during drought stress in ovary and leaf, respectively, and only 14 of these DAS genes were common to both tissues indicating a tissue-specific differences (Mei et al., 2017). These studies suggest that alternative splicing is less frequently used under drought compared to other abiotic stresses. The results here also show genotype-specific differences in DAS responses under drought.

Interestingly, the proteins involved in splicing were also modulated by stress conditions (Ali and Reddy, 2008). In the present study, we found that the levels of two splicing factors (RS31 and SCL30) were significantly upregulated in droughtstressed Otis and Baronesse (Figure 7A). Arabidopsis orthologs of these genes have been found to regulate plant splice site selection and it is possible that changes in their expression will also lead to DAS in barley (Lopato et al., 1996; Yan et al., 2017). Remarkably, most DAS events were genotype-specific in this study indicating differences in AS between the two barley genotypes. Some of these transcript changes led to a switch from one major abundant isoform to an alternative transcript, which became the abundant transcript isoform under drought stress (Figure 7B; Supplementary Figure 2). Such large changes in AS transcript abundances have been described previously in human cancers and were considered as post-transcriptional biological markers of the condition (Climente-González et al., 2017). We found drought induced AS events affecting exon skipping and changes in the selection of alternative 5' and 3' splice sites. But many stress changes led to transcripts that show intron retention. In some cases, the switched transcript under drought led to a transcript with an intron retention (Figure $\mathbf{7 B}$ is one example). Intron retentions alters the length of the 3'UTR and may affect transcript stability or transport from the nucleus (Kalyna et al., 2012; Göhring et al., 2014). Overall, DAS affects a small number of genes in the two genotypes under drought stress but alters the abundance of the gene transcripts in a highly significant manner and it remains to be determined the importance of such changes.

\section{CONCLUSIONS}

Drought tolerance is a complex process involving several thousands of genes associated with various biochemical and physiological processes. In this study, two barley genotypes differing in their drought tolerance (Otis and Baronesse) were compared for their molecular, hormonal, and physiological differences under drought. Otis had better photosynthetic capacity under drought compared to Baronesse, which could be attributed to the differences in gene expression (D1 and D2) associated with PSII stability. The hormone analysis revealed that both genotypes showed significant induction of ABA under stress conditions. Similarly, at the molecular level, many stress responsive genes such as chaperones, aquaporins, and annexins were found to be regulated at similar levels in both genotypes under drought stress. However, a few genes such as $\mathrm{BADH}$ and homeobox TF were highly induced in Otis compared to Baronesse. Importantly, many potential drought tolerance genes such as wax biosynthesis gene (CER1), and two NAC TFs were uniquely induced in Otis under drought stress. On the other hand, genes for WRKY TFs, and PKs were highly downregulated in the drought-stressed Baronesse. Taken together, the overall transcriptional responses were low in drought-tolerant Otis but the genes that could confer drought tolerance were either specifically induced or greatly upregulated in the tolerant genotype and these differences could be important for drought tolerance in barley.

\section{DATA AVAILABILITY STATEMENT}

The datasets generated for this study can be found in online repositories. The names of the repository/repositories and accession number(s) can be found at: European Nucleotide Archive (ENA) at EMBL-EBI under accession number PRJEB40905.

\section{AUTHOR CONTRIBUTIONS}

$\mathrm{AH}$ and $\mathrm{RS}$ conceived the idea. $\mathrm{AH}$ conducted the drought treatments and harvested samples as well as estimation of biochemical parameters. CS and WG performed the bioinformatics analysis of RNA-Seq datasets. VGK assisted with measurements of photosynthesis-related parameters. GG performed qPCR analysis. AH prepared the manuscript with contributions from WG and CS. RS, CS, and AH refined and finalized the draft. All authors reviewed and approved the final manuscript.

\section{FUNDING}

This research was supported in part by the NSF-EPSCoR award 1826836 and NSF-IOS award 1849708 to RS. CS and WG were supported by Scottish Government Rural and Environment Science and Analytical Services division (RESAS).

\section{ACKNOWLEDGMENTS}

Special thanks to Fulbright for giving AH Jordanian Fulbright Scholar Research Award (2019/2020). The authors are also thankful to Dr. Dolores Mornhinweg (USDA-ARS Plant Science and Water Conservation Research Laboratory Stillwater, Oklahoma, USA) for providing the barley seeds used in this study.

\section{SUPPLEMENTARY MATERIAL}

The Supplementary Material for this article can be found online at: https://www.frontiersin.org/articles/10.3389/fpls.2020. 618491/full\#supplementary-material 


\section{REFERENCES}

Ali, G. S., and Reddy, A. S. N. (2008). "Regulation of alternative splicing of premRNAs by stresses," in Nuclear pre-mRNA Processing in Plants. Current Topics in Microbiology and Immunology, eds A. S. N. Reddy and M. Golovkin. (Berlin: Springer Berlin Heidelberg), 257-275.

Ashraf, M., and Foolad, M. R. (2007). Roles of glycine betaine and proline in improving plant abiotic stress resistance. Environ. Exp. Bot. 59, 206-216. doi: 10.1016/j.envexpbot.2005.12.006

Baghyalakshmi, K., Ramchander, S., Raveendran, M., and Jeyaprakash, P. (2020). Unravelling of osmotic genes involved in, drought tolerance in Backcross inbred lines of rice (Oryza sativa L.) cultivars. Res. J. Biotech. 15, 52-60. Available online at: https://www.researchgate.net/profile/Ramchander_ Selvaraj2/publication/342623213_Unravelling_of_Osmotic_genes_involved_ in_Drought_tolerance_in_Backcross_inbred_lines_of_rice_Oryzasativa L_cultivars/links/5efd58a7458515505084919d/Unravelling-of-Osmoticgenes-involved-in-Drought-tolerance-in-Backcross-inbred-lines-of-riceOryzasativa-L-cultivars.pdf

Baker, N. (1991). A possible role for photosystem II in environmental perturbations of photosynthesis. Physiol. Plant. 81, 563-570. doi: 10.1111/j.1399-3054.1991.tb05101.x

Baldoni, E., Bagnaresi, P., Locatelli, F., Mattana, M., and Genga, A. (2016). Comparative leaf and root transcriptomic analysis of two rice Japonica cultivars reveals major differences in the root early response to osmotic stress. Rice 9, 25-45. doi: 10.1186/s12284-016-0098-1

Bandurska, H. (2001). Does proline accumulated in leaves of water deficit stressed barley plants confine cell membrane injuries? II. Proline accumulation during hardening and its involvement in reducing membrane injuries in leaves subjected to severe osmotic stress. Acta Physiol. Plant. 23, 483-490. doi: 10.1007/s11738-001-0059-0

Bandurska, H., and Stroihski, A. (2003). ABA and proline accumulation in leaves and roots of wild (Hordeum spontaneum) and cultivated (Hordeum vulgate 'Maresi') barley genotypes under water deficit conditions. Acta Physiol. Plant 25, 55-61. doi: 10.1007/s11738-003-0036-x

Bartels, D., and Sunkar, R. (2005). Drought and salt tolerance in plants. Crit. Rev. Plant Sci. 24, 23-58. doi: 10.1080/07352680590910410

Benjamini, Y., and Yekutieli, D. (2001). The control of the false discovery rate in multiple testing under dependency. Ann. Statist. 29, 1165-1188. doi: $10.1214 /$ aos/1013699998

Bhattacharjee, A., Khurana, J. P., and Jain, M. (2016). Characterization of rice homeobox genes, OsHOX22 and OsHOX24, and over-expression of OsHOX24 in transgenic Arabidopsis suggest their role in abiotic stress response. Front. Plant Sci. 7:627. doi: 10.3389/fpls.2016.00627

Bi, H., Shi, J., Kovalchuk, N., Luang, S., Bazanova, N., Chirkova, L., et al. (2018). Overexpression of the TaSHN1 transcription factor in bread wheat leads to leaf surface modifications, improved drought tolerance, and no yield penalty under controlled growth conditions. Plant Cell Environ. 41, 2549-2566. doi: 10.1111/pce.13339

Bielach, A., Hrtyan, M., and Tognetti, V. (2017). Plants under stress: involvement of auxin and cytokinin. Int. J. Mol. Sci. 18, 1427-1456. doi: $10.3390 /$ ijms 18071427

Blum, A. (2009). Effective use of water (EUW) and not water-use efficiency (WUE) is the target of crop yield improvement under drought stress. Field Crops Res. 112, 119-123. doi: 10.1016/j.fcr.2009.03.009

Blum, A. (2017). Osmotic adjustment is a prime drought stress adaptive engine in support of plant production. Plant Cell Environ. 40, 4-10. doi: $10.1111 /$ pce. 12800

Borah, P., Sharma, E., Kaur, A., Chandel, G., Mohapatra, T., Kapoor, S., et al. (2017). Analysis of drought-responsive signalling network in two contrasting rice cultivars using transcriptome-based approach. Sci. Rep. 7:42131. doi: 10.1038/srep42131

Bourdenx, B., Bernard, A., Domergue, F., Pascal, S., Le'ger, A., Roby, D., et al. (2011). Overexpression of Arabidopsis ECERIFERUM1 promotes wax verylong-chain alkane biosynthesis and influences plant response to biotic and abiotic stresses. Plant Physiol. 156, 29-45. doi: 10.1104/pp.111.172320

Bray, E. A. (2004). Genes commonly regulated by water-deficit stress in Arabidopsis thaliana. J. Exp. Bot. 55, 2331-2341. doi: 10.1093/jxb/erh270
Bullard, J. H., Purdom, E., Hansen, K. D., and Dudoit, S. (2010). Evaluation of statistical methods for normalization and differential expression in mRNA-Seq experiments. BMC Bioinformatics 11, 94-107. doi: 10.1186/1471-2105-11-94

Burton, R., Shirley, N., King, B., Harvey, A., and Fincher, G. (2004). The CesA. quantitative analysis of transcripts reveals two groups of co-expressed genes. Plant Physiol. 134, 224-236. doi: 10.1104/pp.103.032904

Cafiero, C., Viviani, S., and Nord, M. (2018). Food security measurement in a global context: the food insecurity experience scale. Measurement 116, 146-152. doi: 10.1016/j.measurement.2017.10.065

Cai, R., Zhao, Y., Wang, Y., Lin, Y., Peng, X., Li, Q., et al. (2014). Overexpression of a maize WRKY58 gene enhances drought and salt tolerance in transgenic rice. Plant Cell Tissue Organ Cult. 119, 565-577. doi: 10.1007/s11240-014-0556-7

Calixto, C. P. G., Guo, W., James, A. B., Tzioutziou, N. A., Entizne, J. C., Panter, P. E., et al. (2018). Rapid and dynamic alternative splicing impacts the arabidopsis cold response transcriptome. Plant Cell 30, 1424-1444. doi: $10.1105 /$ tpc. 18.00177

Cantalapiedra, C. P., García-Pereira, M. J., Gracia, M. P., Igartua, E., Casas, A. M., and Contreras-Moreira, B. (2017). Large differences in gene expression responses to drought and heat stress between elite barley cultivar Scarlett and a Spanish landrace. Front. Plant Sci. 8:647. doi: 10.3389/fpls.2017.00647

Carillo, P., and Gibon, Y. (2011). Protocol: Extraction and Determination of Proline. Available online at: http://prometheuswiki.org/tiki-index.php?page= Extraction+and+determination+of+proline (accessed December 6, 2019).

Chen, L., Song, Y., Li, S., Zhang, L., Zou, C., and Yu, D. (2011). The role of WRKY transcription factors in plant abiotic stresses. Biochim. Biophys. Acta. 1819, 120-128. doi: 10.1016/j.bbagrm.2011.09.002

Chen, L. J., Zou, W. S., Fei, C. Y., Wu, G., Li, X. Y., Lin, H. H., et al. (2018). $\alpha$-expansin EXPA4 positively regulates abiotic stress tolerance but negatively regulates pathogen resistance in Nicotiana tabacum. Plant Cell Physiol. 59, 2317-2330. doi: 10.1093/pcp/pcy155

Chen, Y., Han, Y., Zhang, M., Zhou, S., Kong, X., and Wang, W. (2016). Overexpression of the wheat expansin gene TaEXPA2 improved seed production and drought tolerance in transgenic tobacco plants. PLoS ONE 11:e0153494. doi: 10.1371/journal.pone.0153494

Choi, D., Lee, Y., Cho, H. T., and Kende, H. (2003). Regulation of expansin gene expression affects growth and development in transgenic rice plants. Plant Cell 15, 1386-1398. doi: 10.1105/tpc.011965

Clark, G. B., Sessions, A., Eastburn, D. J., and Roux, S. J. (2001). Differential expression of members of the annexin multigene family in Arabidopsis. Plant Physiol. 126, 1072-1084. doi: 10.1104/pp.126.3.1072

Climente-González, H., Porta-Pardo, E., Godzik, A., and Eyras, E. (2017). The functional impact of alternative splicing in cancer. Cell Rep. 20, 2215-2226. doi: 10.1016/j.celrep.2017.08.012

Colebrook, E., Thomas, S., Philips, A., and Hedden, P. (2014). The role of gibberellin signalling in plant responses to abiotic stress. J. Exp. Bot. 217, 67-75. doi: $10.1242 /$ jeb. 089938

Cosgrove, D. (2000). Expansive growth of plant cell walls. Plant Physiol. Biochem. 38, 109-124. doi: 10.1016/S0981-9428(00)00164-9

Cosgrove, D. (2015). Plant expansins: diversity and interactions with plant cell walls. Curr. Opin. Plant Biol. 25, 162-172. doi: 10.1016/j.pbi.2015.05.014

Daszkowska-Golec, A. (2016). "The role of abscisic acid in drought stress: how ABA helps plants to cope with drought stress," in Drought Stress Tolerance in Plants, Vol 2, eds M. Hossain, S. Wani, S. Bhattacharjee, D. Burritt, L. S. Tran. (Cham: Springer), 123-151. doi: 10.1007/978-3-319-32423-4_5

Dawson, I., Russell, J., Powell, W., Steffenson, B., Thomas, W., and Waugh, R. (2015). Barley: a translational model for adaptation to climate change. New Phytol. 206, 913-931. doi: 10.1111/nph.13266

de Mezer, M., Turska-Taraska, A., Kaczmarek, Z., Glowacka, K., Swarcewicz, B., and Rorat, T. (2014). Differential physiological and molecular response of barley genotypes to water deficit. Plant Physiol. Biochem. 80, 234-248. doi: 10.1016/j.plaphy.2014.03.025

Deng, Q., Luo, X., Chen, Y., Zhou, Y., Zhou, Y., and Zhang, F. (2018). Transcriptome analysis of phosphorus stress responsiveness in the seedlings of Dongxiang wild rice (Oryza rufpogon Grif.). Biol. Res. 51, 7-19. doi: 10.1186/s40659-018-0155-x

Diab, A., Teulat-Merah, B., This, D., Ozturk, N. Z., Benscher, D., and Sorrells, M. E. (2004). Identification of drought-inducible genes and differentially 
expressed sequence tags in barley. Theor. Appl. Genet. 109, 1417-1425. doi: 10.1007/s00122-004-1755-0

Ding, W. W., Fang, W. B., Shi, S. Y., Zhao, Y. Y., Li, X. J., and Xiao, K. (2016). Wheat WRKY type transcription factor gene TaWRKY1 is essential in mediating drought tolerance associated with an ABA-dependent pathway. Plant Mol. Biol. Rep. 34, 1111-1126. doi: 10.1007/s11105-0160991-1

Duque, P. (2011). A role for SR proteins in plant stress responses. Plant Signal. Behav. 6, 49-54. doi: 10.4161/psb.6.1.14063

Ereful, N. C., Liu, L., Greenland, A., Powell, W., Mackay, I., and Leung, H. (2020). RNA-seq reveals differentially expressed genes between two indica inbred rice genotypes associated with drought-yield QTLs. Agron 10, 621-640. doi: 10.3390/agronomy10050621

Gahluat, V., Jaiswal, V., Kumar, A., and Gupta, P. K. (2016). Transcription factors involved in drought tolerance and their possible role in developing drought tolerant cultivars with emphasis on wheat (Triticum aestivum L.). Theor. Appl. Genet. 129, 2019-2042. doi: 10.1007/s00122-016-2794-z

Gajdošová, S., Spíchal, L., Kamínek, M., Hoyerová, K., Novák, O., Dobrev, P., et al. (2011). Distribution, biological activities, metabolism, and the conceivable function of cis-zeatin-type cytokinins in plants. J. Exp. Bot. 62, 2827-2840. doi: $10.1093 / \mathrm{jxb} / \mathrm{erq} 457$

García-Morales, S., Gómez-Merino, F., and Trejo-Téllez, L. (2014). NAC transcription factor expression, amino acid concentration and growth of elite rice cultivars upon salt stress. Acta Physiol. Plant. 36, 1927-1936. doi: $10.1007 / \mathrm{s} 11738-014-1569-\mathrm{x}$

Giraldo, P., Benavente, E., Manzano-Agugliaro, F., and Gimenez, E. (2019). Worldwide research trends on wheat and barley: a bibliometric comparative analysis. Agron 9, 352-370. doi: 10.3390/agronomy9070352

Göhring, J., Jacak, J., and Barta, A. (2014). Imaging of endogenous messenger RNA splice variants in living cells reveals nuclear retention of transcripts inaccessible to nonsense-mediated decay in Arabidopsis. Plant Cell 26, 754-764. doi: 10.1105/tpc.113.118075

Gorantla, M., Babu, P. R., Lachagari, V. B. R., Feltus, F. A., Paterson, A. H., and Reddy, A. R. (2005). Functional genomics of drought-stress response in rice: transcript mapping of annotated unigenes of an indica rice (Oryza sativa L. cv. Nagina 22). Curr. Sci. 89, 496-514. Available online at: http://www.iisc.ernet.in/ currsci/aug102005/496.pdf

Guo, P., Baum, M., Grando, S., Ceccarelli, S., Bai, G., Li, R., et al. (2009). Differentially expressed genes between drought-tolerant and drought-sensitive barley genotypes in response to drought stress during the reproductive stage. $J$. Exp. Bot. 60, 3531-3544. doi: 10.1093/jxb/erp194

Guo, Y., Ping, W., Chen, J., Zhu, L., Zhao, Y., Guo, J., et al. (2019). Meta-analysis of the effects of overexpression of WRKY transcription factors on plant responses to drought stress. BMC Genetics 20, 63-77. doi: 10.1186/s12863-019-0766-4

Gupta, A., and Senthil-Kuma, M. (2017). Transcriptome changes in Arabidopsis thaliana infected with Pseudomonas syringae during drought recovery. Sci. Rep. 7:9124. doi: 10.1038/s41598-017-09135-y

Ha, S., Vankova, R., KazukoYamaguchi-Shinozaki, K., Shinozaki, K., and Tran, L. S. (2012). Cytokinins: metabolism and function in plant adaptation to environmental stresses. Trends Plant Sci. 17, 172-179. doi: 10.1016/j.tplants.2011.12.005

Hao, Y. J., Wei, W., Song, Q. X., Chen, H. W., Zhang, Y. Q., Wang, F., et al. (2011). Soybean NAC transcription factors promote abiotic stress tolerance and lateral root formation in transgenic plants. Plant J. 68, 302-313. doi: 10.1111/j.1365-313X.2011.04687.x

Harb, A., Krishnan, A., Ambavaram, M. M., and Pereira, A. (2010). Molecular and physiological analysis of drought stress in Arabidopsis reveals early responses leading to acclimation in plant growth. Plant Physiol. 54, 1254-1271. doi: $10.1104 /$ pp. 110.161752

Harb, A., and Samarah, N. (2015). Physiological and molecular responses to controlled severe drought in two barley (Hordeum Vulgare L.) genotypes. J. Crop Improv. 29, 82-94. doi: 10.1080/15427528.2014.976802

Hasanuzzaman, M., Shabala, L., Brodribb, T., Zhou, M., and Shabala, S. (2019). Understanding physiological and morphological traits contributing to drought tolerance in barley. J. Agron. Crop Sci. 205, 129-140. doi: 10.1111/jac.12307

Hayat, S., Hayat, Q., Alyemeni, M. N., Wani, A., Pichtel, J., and Ahmad, A. (2012). Role of proline under changing environments. Plant Signal. Behav. 7, 1456-1466. doi: $10.4161 /$ psb.21949
He, X., Zeng, J., Cao, F., Ahmed, I. M., Zhang, G., Vincze, E., et al. (2015). HvEXPB7, a novel $\beta$-expansin gene revealed by the root hair transcriptome of Tibetan wild barley, improves root hair growth under drought stress. J. Exp. Bot. 66, 7405-7749. doi: 10.1093/jxb/erv436

Heath, R., and Packer, L. (1968). Photoperoxidation in isolated chloroplasts. I. Kinetics and stoichiometry of fatty acid peroxidation. Arch. Biochem. Biophys. 125, 189-198. doi: 10.1016/0003-9861(68)90654-1

Hiei, Y., Ishida, Y., and Komari, T. (2014). Progress of cereal transformation technology mediated by Agrobacterium tumefaciens. Front. Plant Sci. 5, 628-640. doi: 10.3389/fpls.2014.00628

Huang, Q., Wang, Y., Li, B., Chang, J., Chen, M., and Li, K. (2015). TaNAC29, a NAC transcription factor from wheat, enhances salt and drought tolerance in transgenic Arabidopsis. BMC Plant Biol. 15, 268-283. doi: 10.1186/s12870-015-0644-9

Hübner, S., Korol, A. B., and Schmid, K. J. (2015). RNA-Seq analysis identifies genes associated with differential reproductive success under drought-stress in accessions of wild barley Hordeum spontaneum. BMC Plant Biol. 5, 134-148. doi: 10.1186/s12870-015-0528-z

Hughes, J., Hepworth, C., Dutton, C., Dunn, J., Hunt, L., Stephens, J., et al. (2017). Reducing stomatal density in barley improves drought tolerance without impacting on yield. Plant Physiol. 174, 776-787. doi: 10.1104/pp.16. 01844

Jami, S. K., Clark, G. B., Turlapati, S. A., Handley, C. A., Roux, S. J., and Kirti, P. B. (2008). Ectopic expression of an annexin from Brassica juncea confers tolerance to abiotic and biotic stress treatments in transgenic tobacco. Plant Physiol. Biochem. 46, 1019-1030. doi: 10.1016/j.plaphy.2008.07.006

Janiak, A., Kwasniewski, M., Sowa, M., Kuczyńska, A., Mikołajczak, K., Ogrodowicz, P., et al. (2019). Insights into barley root transcriptome under mild drought stress with an emphasis on gene expression regulatory mechanisms. Int. J. Mol. Sci. 20, 6139-6164. doi: 10.3390/ijms20246139

Joshi, R., Wani, S. H., Singh, B., Bohra, A., Dar, Z. A., Lone, A. A., et al. (2016). Transcription factors and plants response to drought stress: current understanding and future directions. Front. Plant Sci. 7, 1029-1044. doi: $10.3389 /$ fpls.2016.01029

Kalyna, M., Simpson, C. G., Syed, N. H., Lewandowska, D., Marquez, Y., Kusenda, B., et al. (2012). Alternative splicing and nonsense-mediated decay modulate expression of important regulatory genes in Arabidopsis. Nucleic Acids Res. 40, 2454-2469. doi: 10.1093/nar/gkr932

Kapilan, R., Vaziri, M., and Zwiazek, J. J. (2018). Regulation of aquaporins in plants under stress. Biol. Res. 51, 4-16. doi: 10.1186/s40659-018-0152-0

Kim, W., Iizumi, T., and Nishimori, M. (2019). Global patterns of crop production losses associated with droughts from 1983 to 2009. J. Appl. Meteorol. Climatol. 58, 1233-1244. doi: 10.1175/JAMC-D-18-0174.1

Konopka-Postupolska, D., Clark, G., Goch, G., Debski, J., Floras, K., Cantero, A., et al. (2009). The role of annexin 1 in drought stress in Arabidopsis. Plant Physiol. 150, 1394-1410. doi: 10.1104/pp.109.135228

Korver, R. A., Koevoets, I. T., and Testerink, C. (2018). Out of shape during stress: a key role for auxin. Trends Plant Sci. 23, 783-793. doi: 10.1016/j.tplants.2018.05.011

Kosma, D., Bourdenx, B., Bernard, A., Parsons, E., Lü, S., Joubès, J., et al. (2009). The impact of water deficiency on leaf cuticle lipids of Arabidopsis. Plant Physiol. 151, 918-1929. doi: 10.1104/pp.109.141911

Kudo, T., Makita, N., Kojima, M., Tokunaga, H., and Sakakibara, H. (2012). Cytokinin activity of cis-Zeatin and phenotypic alterations induced by overexpression of putative cis-Zeatin-O-glucosyltransferase in rice. Plant Physiol.160, 319-331. doi: 10.1104/pp.112.196733

Laloum, T., Martín, G., and Duque, P. (2018). Alternative splicing control of abiotic stress responses. Trends Plant Sci. 23, 140-150. doi: $10.1016 /$ j.tplants.2017.09.019

Law, C., Chen, Y., Shi, W., and Smyth, G. (2014). voom: precision weights unlock linear model analysis tools for RNA-seq read counts. Genome Biol. 15:R29. doi: 10.1186/gb-2014-15-2-r29

Lehti-Shiu, M., Zou, C., Hanada, K., and Shiu, S. H. (2009). Evolutionary history and stress regulation of plant receptor-like kinase/pelle genes. Plant Physiol. 150, 12-26. doi: 10.1104/pp.108.134353

Lesk, C., Rowhani, P., and Ramankutty, N. (2016). Influence of extreme weather disasters on global crop production. Nature 529, 84-87. doi: 10.1038 /nature16467 
Li, S., Yu, X., Cheng, Z., Zeng, C., Li, W., Zhang, L., et al. (2020). Large-scale analysis of the cassava transcriptome reveals the impact of cold stress on alternative splicing. J. Exp. Bot. 71, 422-434. doi: 10.1093/jxb/erz444

Liu, Q., Li, X., Yan, S., Yu, T., Yang, J., Dong, J., et al. (2018). OsWRKY67 positively regulates blast and bacteria blight resistance by direct activation of PR genes in rice. BMC Plant Biol. 18, 257-270. doi: 10.1186/s12870-018-1479-y

Liu, W. J., Yuan, S., Zhang, N. H., Lei, T., Duan, H. G., and Liang, H. G. (2006). Effect of water stress on photosystem 2 in two wheat cultivars. Physiol. Plant. 50, 597-602. doi: 10.1007/s10535-006-0094-1

Liu, Z., Qin, J., Tian, X., Xu, S., Wang, Y., Li, H., et al. (2018). Global profiling of alternative splicing landscape responsive to drought, heat and their combination in wheat (Triticum aestivum L.). Plant Biotechnol. J. 16, 714-726. doi: $10.1111 /$ pbi. 12822

Livak, K., and Schmittgen, T. (2001). Analysis of relative gene expression data using real-time quantitative PCR and the 2- $\Delta \Delta$ CT method. Methods 25, 402-408. doi: $10.1006 /$ meth.2001.1262

Lobell, D. B., Schlenker, W., and Costa-Roberts, J. (2011). Climate trends and global crop production since 1980. Science 333, 616-620. doi: 10.1126/science.1204531

Lombardi, M. (2012). The barley expansin family. (Ph.D. dissertation). University of Adelaide, Waite, MN.

Lopato, S., Waigmann, E., and Barta, A. (1996). Characterization of a novel arginine/serine-rich splicing factor in Arabidopsis. Plant Cell 8, 2255-2264. doi: $10.1105 /$ tpc.8.12.2255

Lv, Y., Xu, L., Dossa, K., Zhou, K., Zhu, M., Xie, H., et al. (2019). Identification of putative drought-responsive genes in rice using gene co-expression analysis. Bioinformation 15, 480-489. doi: 10.6026/97320630015480

Marowa, P., Ding, A., and Kong, Y. (2016). Expansins: roles in plant growth and potential applications in crop improvement. Plant Cell Rep. 35, 949-965. doi: 10.1007/s00299-016-1948-4

Martin, M. (2011). Cutadapt removes adapter sequences from high-throughput sequencing reads. EMBnet J. 17, 10-12. doi: 10.14806/ej.17.1.200

Mei, W., Liu, S., Schnable, J. C., Yeh, C. T., Springer, N. M., Schnable, P. S., et al. (2017). A comprehensive analysis of alternative splicing in paleopolyploid maize. Front. Plant Sci. 8:694. doi: 10.3389/fpls.2017.00694

Mejri, M., Siddique, K., Saif, T., Abdelly, C., and Hessini, K. (2016). Comparative effect of drought duration on growth, photosynthesis, water relations, and solute accumulation in wild and cultivated barley species. J. Plant Nutr. Soil Sci. 179, 327-335. doi: 10.1002/jpln.201500547

Meza, I., Siebert, S., Döll, P., Kusche, J., Herbert, C., Rezaei, E., et al. (2020). Globalscale drought risk assessment for agricultural systems. Nat. Hazards Earth Syst. Sci. 20, 695-712. doi: 10.5194/nhess-20-695-2020

Mornhinweg, D. W., Bregitzer, P. P., Porter, D. R., Peairs, F. B., Baltensperger, D. D., Hein, G. L., et al. (2009). Registration of Sidney Spring feed barley resistant to Russian wheat aphid. J. Plant Regist. 3, 214-218. doi: 10.3198/jpr2009.04.0205crc

Mudgil, Y., Shiu, S. H., Stone, S., Salt, J., and Goring, J. (2004). A Large complement of the predicted Arabidopsis ARM repeat proteins are members of the U-Box E3 ubiquitin ligase family. Plant Physiol. 134, 59-66. doi: 10.1104/pp.103.029553

Munemasa, S., Hauser, F., Park, J., Waadt, R., Brandt, B., and Schroeder, J. (2015). Mechanisms of abscisic acid-mediated control of stomatal Aperture. Curr. Opin. Plant Biol. 28, 154-162. doi: 10.1016/j.pbi.2015.10.010

Nakamura, T., Nomura, M., Jagendorf, A., Ueda, A., and Takabe, T. (2001). An isozyme of betaine aldehyde dehydrogenase in barley. Plant Cell Physiol. 42, 1088-1092. doi: 10.1093/pcp/pce136

Nakashima, K., Tran, L. S., Nguyen, D. V., Fujita, M., Maruyama, K., Todaka, D., et al. (2007). Functional analysis of a NAC-type transcription factor OsNAC6 involved in abiotic and biotic stress-responsive gene expression in rice. Plant $J$. 51, 617-630. doi: 10.1111/j.1365-313X.2007.03168.x

Nakashima, K., Yamaguchi-Shinozaki, K., and Shinozaki, K. (2014). The transcriptional regulatory network in the drought response and its crosstalk in abiotic stress responses including drought, cold, and heat. Front. Plant Sci. 5:170. doi: 10.3389/fpls.2014.00170

Narsai, R., Wang, C., Chen, J., Wu, J., Shou, H., Whelan, J., et al. (2013). Antagonistic, overlapping and distinct responses to biotic stress in rice (Oryza sativa) and interactions with abiotic stress. BMC Genomics 14, 93-114. doi: 10.1186/1471-2164-14-93
Nelissen, H., Sun, X. H., Rymen, B., Jukumaru, Y., Kojima, M., and Takebayashi, Y. (2018). The reduction in maize leaf growth under mild drought affects the transition between cell division and cell expansion and cannot be restored by elevated gibberellic acid levels. Plant Biotechnol. J. 16, 615-627. doi: $10.1111 /$ pbi.12801

Omena-Garcia, R. P., Martins, A. O., Medeiros, D. B., Vallarino, J. G., Ribeiro, D. M., and Fernie, A. R. (2019). Growth and metabolic adjustments in response to gibberellin deficiency in drought stressed tomato plants. Environ. Exp. Bot. 159, 95-107. doi: 10.1016/j.envexpbot.2018.12.011

Ouyang, W., Struik, P., Yin, X., and Yang, J. (2017). Stomatal conductance, mesophyll conductance, and transpiration efficiency in relation to leaf anatomy in rice and wheat genotypes under drought. J. Exp. Bot. 68, 5191-5205. doi: $10.1093 / \mathrm{jxb} / \mathrm{erx} 314$

Ozturk, N. Z., Talamè, V., Deyholos, M., Michalowski, C., Galbraith, D., Gozukirmizi, N., et al. (2002). Monitoring large-scale changes in transcript abundance in drought- and salt-stressed barley. Plant Mol. Biol. 48, 551-573. doi: 10.1023/A:1014875215580

Patro, R., Duggal, G., Love, M. I., Irizarry, R. A., and Kingsford, C. (2017). Salmon provides fast and bias-aware quantification of transcript expression. Nat. Methods. 14, 417-419. doi: 10.1038/nmeth.4197

Pavlu, J., Novák, J., Koukalová, V., Luklová, M., and Brzobohatý, B., Cerný, M. (2018). Cytokinin at the crossroads of abiotic stress signalling pathways. Int. J. Mol. Sci. 19, 2450-2486. doi: 10.3390/ijms19082450

Peleg, Z., and Blumwald, E. (2011). Hormone balance and abiotic stress tolerance in crop plants. Curr. Opin. Plant Biol. 14, 290-295. doi: 10.1016/j.pbi.2011.02.001

Pieczynski, M., Wyrzykowska, A., Milanowska, K., Boguszewska-Mankowska, D., Zagdanska, B., Karlowski, W., et al. (2018). Genome wide identification of genes involved in the potato response to drought indicates functional evolutionary conservation with Arabidopsis plants. Plant Biotechnol. J. 16, 603-614. doi: 10.1111/pbi.12800

Plaza-Wüthrich, S., Blösch, R., Rindisbacher, A., Cannarozzi, G., and Tadele, Z. (2016). Gibberellin deficiency confers both lodging and drought tolerance in small cereals. Front. Plant Sci. 7:643. doi: 10.3389/fpls.2016.00643

Priya, M., Dhanker, O., Siddique, K. H. M., HanumanthaRao, B., Nair, R., Pandey, S., et al. (2019). Drought and heat stress-related proteins: an update about their functional relevance in imparting stress tolerance in agricultural crops. Theor. Appl. Genet. 132, 1607-1638. doi: 10.1007/s00122-01903331-2

Quigley, F., Rosenberg, J. M., Shachar-Hill, Y., and Bohnert, H. (2001). From genome to function: the Arabidopsis aquaporins. Genome Biol. 3:research0001. doi: 10.1186/gb-2001-3-1-research0001

Ramegowda, V., Krishnan, A., and Pereira, A. (2014). Rice GROWTH UNDER DROUGHT KINASE is required for drought tolerance and grain yield under normal and drought stress conditions. Plant Physiol. 166, 1634-1645. doi: $10.1104 /$ pp.114.248203

Rapazote-Flores, P., Bayer, M., Milne, L., Mayer, C. D., Fuller, J., Guo, W., et al. (2019). BaRTv1.0: an improved barley reference transcript dataset to determine accurate changes in the barley transcriptome using RNA-seq. BMC Genomics 20, 968-985. doi: 10.1186/s12864-019-6243-7

Raudvere, U., Kolberg, L., Kuzmin, I., Arak, T., Adler, P., Peterson, H., et al. (2019). g: Profiler: a web server for functional enrichment analysis and conversions of gene lists (2019 update). Nucl. Acid. Res. 47, W191-W198. doi: 10.1093/nar/gkz369

Ray, S., Dansana, P. K., Giri, J., Deveshwar, P., Arora, R., et al. (2011). Modulation of transcription factor and metabolic pathway genes in response to water-deficit stress in rice. Funct. Integr. Genomic. 11, 157-178. doi: 10.1007/s10142-010-0187-y

Reddy, A. S. N., Marquez, Y., Kalyna, M., and Barta, A. (2013). Complexity of the alternative splicing landscape in plants. Plant Cell 25, 3657-3683. doi: 10.1105/tpc.113.117523

Ritchie, M. E., Phipson, B., Wu, D., Hu, Y., Law, C. W., Shi, W., et al. (2015). Limma powers differential expression analyses for RNA-sequencing and microarray studies. Nucleic Acids Res. 43:e47. doi: 10.1093/nar/gkv007

Ryu, M., Cho, S. K., Hong, Y., Kim, J., Kim, J. H., Kim, G. M., et al. (2019). Classification of barley U-box E3 ligases and their expression patterns in response to drought and pathogen stresses. BMC Genomics 20, 326-341. doi: $10.1186 / \mathrm{s} 12864-019-5696-\mathrm{z}$ 
Sah, S. K., Reddy, K. R., and Li, J. (2016). Abscisic acid and abiotic stress tolerance in crop plants. Front. Plant Sci. 7:571. doi: 10.3389/fpls.2016. 00571

Sallam, A., Alqudah, A., Dawood, M., Baenziger, P., and Börner, A. (2019). Drought stress tolerance in wheat and barley: advances in physiology, breeding and genetics research. Int. J. Mol. Sci. 20, 3137-3175. doi: 10.3390/ijms20133137

Schäfer, M., Brütting, C., Meza-Canales, I., Großkinsky, D., Vankova, R., and Baldwin, I. (2015). The role of cis-zeatin-type cytokinins in plant growth regulation and mediating responses to environmental interactions. J. Exp. Bot. 66, 4873-4884. doi: 10.1093/jxb/erv214

Scharwies, J. D. (2017). The role of aquaporins in plant responses to drought. (Ph.D. dissertation). The University of Adelaide, Waite, MN.

Schmid, I., Franzaring, J., Müller, M., Brohon, N., Calvo, O. C., Högy, P., et al. (2016). Drought stress effects of $\mathrm{CO}_{2}$ enrichment and drought on photosynthesis, growth and yield of an old and a modern barley cultivar. $J$. Agron. Crop Sci. 202, 81-95.

Schonfeld, M. A., Johnson, R. C., Carver, B. F., and Mornhinweg, D. W. (1988). Water relations in winter wheat as drought resistance indicator. Crop Sci. 28, 526-531.

Shaik, R., and Ramakrishna, W. (2012). Bioinformatic analysis of epigenetic and microRNA mediated regulation of drought responsive genes in rice. PLOS ONE 7:e49331. doi: 10.1371/journal.pone.0049331

Sharma, M., and Pandey, G. K. (2016). Expansion and function of repeat domain proteins during stress and development in plants. Front. Plant Sci. 6:1218. doi: 10.3389/fpls.2015.01218

Sharma, M., Singh, A., Shankar, A., Pandey, A., Baranwal, V., Kapoor, S., et al. (2014). Comprehensive expression analysis of rice Armadillo gene family during abiotic stress and development. DNA Res. 21, 267-283. doi: 10.1093/dnares/dst056

Shim, J. S., Oh, N., Chung, P. J., Kim, Y. S., Choi, Y. D., and Kim, J. K. (2018). Overexpression of OsNAC14 improves drought tolerance in rice. Front. Plant Sci. 9:310. doi: 10.3389/fpls.2018.00310

Silveira, R. D. D., Abreu, F. R. M., Mamidi, S., McClean, P. E., Vianello, R. P., Lanna, A. C., et al. (2015). Expression of drought tolerance genes in tropical upland rice cultivars (Oryza sativa). Genet. Mol. Res. 14, 8181-8200. doi: 10.4238/2015.July.27.6

Talamé, V., Ozturk, N. Z., Bohnert, H., and Tuberosa, R. (2007). Barley transcript profiles under dehydration shock and drought stress treatments: a comparative analysis. J. Exp. Bot. 58, 229-240. doi: 10.1093/jxb/erl163

Törönen, P., Medlar, A., and Holm, L. (2018). PANNZER2: a rapid functional annotation web server. Nucl. Acid Res. 46, W84-W88. doi: 10.1093/nar/gky350

Ullah, A., Manghwar, H., Shaban, M., Khan, A., Akbar, A., Ali, U., et al. (2018). Phytohormones enhanced drought tolerance in plants: a coping strategy. Environ. Sci. Pollut. Res. 25, 33103-33118. doi: 10.1007/s11356-018-3364-5

Vishwakarma, K., Upadhyay, N., Kumar, N., Yadav, G., Singh, J., and Mishra, R. K. (2017). Abscisic acid signaling and abiotic stress tolerance in plants: a review on current knowledge and prospects. Front. Plant Sci. 8, 161-173. doi: 10.3389/fpls.2017.00161

Wang, X., Chen, Z. H., Yang, C., Zhang, X., and Jin, G., Chen, G., et al. (2018). Genomic adaptation to drought in wild barley is driven by edaphic natural selection at the Tabigha evolution slope. Proc. Natl. Acad. Sci. U.S.A. 115, 5223-5228. doi: 10.1073/pnas.1721749115

Wang, Z., and Dane, F. (2013). NAC (NAM/ATAF/CUC) transcription factors in different stresses and their signaling pathway. Acta Physiol. Plant 35, 1397-1408. doi: 10.1007/s11738-012-1195-4

Wu, H., Shi, S., Lu, X., Li, T., Wang, J., Liu, T., et al. (2019). Expression analysis and functional characterization of CER1 family genes involved in very-long-chain alkanes biosynthesis in Brachypodium distachyon. Front. Plant. Sci. 10:1389. doi: 10.3389/fpls.2019.01389

Wu, X. L., Shiroto, Y., Kishitani, S., Ito, Y., and Toriyama, K. (2009). Enhanced heat and drought tolerance in transgenic rice seedlings overexpressing OsWRKY11 under the control of HSP101 promoter. Plant Cell Rep. 28, 21-30. doi: 10.1007/s00299-008-0614-X
Wu, Y., Thorne, E. T., Sharp, R. E., and Cosgrove, D. (2001). Modification of expansin transcript levels in the maize primary root at lower water potentials. Plant Physiol. 126, 1471-1479. doi: 10.1104/pp.126.4.1471

Xiang, J., Zhou, X., Zhang, X., Liu, A., Xiang, Y., Yan, M., et al. (2018). The Arabidopsis AtUNC-93 acts as a positive regulator of abiotic stress tolerance and plant growth via modulation of ABA signaling and $\mathrm{K}(+)$ homeostasis. Front. Plant Sci. 9,718-733. doi: 10.3389/fpls.2018.00718

Xing, H. T., Guo, P., Xia, X. L., and Yin, W. L. (2011). PdERECTA, a leucine-rich repeat receptor-like kinase of poplar, confers enhanced water use efficiency in Arabidopsis. Planta 234, 229-241. doi: 10.1007/s00425-011-1389-9

Xu, Q., Feng, W. J., Peng, H. R., Ni, Z. F., and Sun, Q. X. (2014). TaWRKY71, a WRKY transcription factor from wheat, enhances tolerance to abiotic stress in transgenic Arabidopsis thaliana. Cereal Res. Commun. 42, 47-57. doi: 10.1556/CRC.2013.0051

Yamaguchi, S. (2008). Gibberellin metabolism and its regulation. Annu. Rev. Plant Biol. 59, 225-251. doi: 10.1146/annurev.arplant.59.032607.092804

Yan, Q., Xia, X., Sun, Z., and Fang, Y. (2017). Depletion of Arabidopsis SC35 and SC35-like serine/arginine-rich proteins affects the transcription and splicing of a subset of genes. PLoS Genet. 13:e1006663. doi: 10.1371/journal.pgen.1006663

Yang, J., Zhang, G., An, J., Li, Q., Chen, Y., and Zhao, X. (2020). Expansin gene TaEXPA2 positively regulates drought tolerance in transgenic wheat (Triticum aestivum L.). Plant Sci. 298, doi: 10.1016/j.plantsci.2020.110596

Yang, Y. W., Chen, H. C., Jen, W. F., Liu, L. Y., and Chang, M. C. (2015). Comparative transcriptome analysis of shoots and roots of TNG67 and TCN1 rice seedlings under cold stress and following subsequent recovery: insights into metabolic pathways, phytohormones, and transcription factors. PLOS ONE 10:e0131391. doi: 10.1371/journal.pone.0131391

Zadoks, C. J., Chang, T. T., and Konzak, C. F. (1974). A decimal code for the growth stages of cereals. Weed Res. 14, 415-421. doi: 10.1111/j.1365-3180.1974.tb01084.x

Zeng, X., Bai, L., Wei,1, Z., Yuan, H., and Wang, Y., Xu, Q., et al. (2016). Transcriptome analysis revealed the drought-responsive genes in Tibetan hulless barley. BMC Genomics 17, 386-398. doi: 10.1186/s12864-0162685-3

Zhang, F., Zhou, Y., Zhang, M., Luo, X., and Xie, J. (2017). Effects of drought stress on global gene expression profile in leaf and root samples of Dongxiang wild rice (Oryza rufipogon). Biosci. Rep. 37:BSR20160509. doi: 10.1042/BSR20160509

Zhang, Y., and Wang, L. (2005). The WRKY transcription factor superfamily: its origin in eukaryotes and expansion in plants. BMC Evol. Biol. 5:1.

Zheng, Y., Jiao, C., Sun, H., Rosli, H. G., Pombo, M. A., Zhang, P., et al. (2016). iTAK: a program for genome-wide prediction and classification of plant transcription factors, transcriptional regulators, and protein kinases. Mol. Plant 9,1667-1670. doi: 10.1016/j.molp.2016.09.014

Zhou, J., Wang, X., Jiao, Y., Qin, Y., Liu, X., et al. (2007). Global genome expression analysis of rice in response to drought and high-salinity stresses in shoot, flag leaf, and panicle. Plant Mol. Biol. 63, 591-608. doi: 10.1007/s11103-0069111-1

Zwack, P., and Rashotte, A. (2015). Interactions between cytokinin signalling and abiotic stress responses. J. Exp. Bot. 66, 4863-4871. doi: 10.1093/jxb/e rv172

Conflict of Interest: The authors declare that the research was conducted in the absence of any commercial or financial relationships that could be construed as a potential conflict of interest.

Copyright (c) 2020 Harb, Simpson, Guo, Govindan, Kakani and Sunkar. This is an open-access article distributed under the terms of the Creative Commons Attribution License (CC BY). The use, distribution or reproduction in other forums is permitted, provided the original author(s) and the copyright owner(s) are credited and that the original publication in this journal is cited, in accordance with accepted academic practice. No use, distribution or reproduction is permitted which does not comply with these terms. 